\title{
Community Violence and Youth: Affect, Behavior, Substance Use, and Academics
}

\author{
Michele Cooley-Strickland · Tanya J. Quille • \\ Robert S. Griffin · Elizabeth A. Stuart • \\ Catherine P. Bradshaw · Debra Furr-Holden
}

Published online: 27 May 2009

(c) The Author(s) 2009. This article is published with open access at Springerlink.com

\begin{abstract}
Community violence is recognized as a major public health problem (WHO, World Report on Violence and Health, 2002) that Americans increasingly understand has adverse implications beyond inner-cities. However, the majority of research on chronic community violence exposure focuses on ethnic minority, impoverished, and/or crime-ridden communities while treatment and prevention focuses on the perpetrators of the violence, not on the youth who are its direct or indirect victims. School-based treatment and preventive interventions are needed for children at elevated risk for exposure to community violence. In preparation, a longitudinal, community epidemiological study, The Multiple Opportunities to Reach Excellence (MORE) Project, is being fielded to address some of the methodological weaknesses presented in previous studies. This study was designed to better understand the impact of children's chronic exposure to community violence on their emotional, behavioral, substance use, and academic functioning with an overarching goal to identify malleable risk and protective factors which can be targeted in preventive and intervention programs. This paper describes the MORE Project, its conceptual underpinnings,
\end{abstract}

M. Cooley-Strickland · T. J. Quille · R. S. Griffin ·

E. A. Stuart - C. P. Bradshaw - D. Furr-Holden

Department of Mental Health, Bloomberg School of Public

Health, Johns Hopkins University, Baltimore, MD, USA

M. Cooley-Strickland ( $\square)$

Center for Culture and Health, Department of Psychiatry,

NPI-Semel Institute for Neuroscience, University

of California-Los Angeles, 760 Westwood Plaza,

Box 62, Los Angeles, CA 90024-1759, USA

e-mail: MCooley@mednet.ucla.edu goals, and methodology, as well as implications for treatment and preventive interventions and future research.

Keywords Community violence . Children and youth . Urban · African American - Internalizing · Externalizing · Substance use $\cdot$ Academic $\cdot$ Prevention

Prospective longitudinal studies involving large epidemiological samples of children exposed to varying levels of community violence are needed to further understand the complex risk and protective factors associated with living in violent neighborhoods. Few exist. This paper describes one such study currently underway, its conceptual underpinnings, goals, and methodology, as well as implications for treatment and preventive interventions and future research. The purpose is to explicate the foundation for such a body of work, its challenges, and motivate future research and clinical intervention on the effects of chronic community violence on youth. The fielding title of this longitudinal, community epidemiological study is the Multiple Opportunities to Reach Excellence (MORE) Project. It is one attempt to address methodological weaknesses of cross-sectional and other less rigorous study designs to better understand the impact of children's exposure to community violence on their emotional, behavioral, substance use, and academic functioning. An overarching goal of the study is to identify malleable risk and protective factors that can be targeted through later preventive and intervention programs.

Community violence is recognized as a major public health problem (World Health Organization 2002) that Americans increasingly understand has adverse implications beyond inner-cities. However, the majority of research on chronic community violence focuses on those most 
directly impacted: ethnic minority, impoverished, and crime-ridden communities. Much of the extant research, treatment, and preventive interventions focus on the perpetrators of the violence, not on the youth who are its direct or indirect victims. The public health impact of living in violent communities is significant, particularly for children. Among the emotional, behavioral and academic achievement correlates are anxiety, depression, disruptive and aggressive behavior, substance use, school disengagement, and academic failure (Cooley-Quille et al. 2001; GormanSmith and Tolan 1998; Hutcheson 1998; Jenkins and Bell 1994; Lorion et al. 1999; Osofsky et al. 1993; Pynoos et al. 1987; Schwab-Stone et al. 1999; Singer et al. 1995) which may have profound effects on children's development from early childhood into adolescence and beyond.

School-based treatment and preventive interventions are needed for children at elevated risk for exposure to community violence among those whose exposure impairs their ability to function developmentally appropriately and achieve academic success. Although there have been significant advancements in community violence research in the past decade, many methodological shortcomings pervade (e.g., psychometrically unsupported instruments, convenience samples, retrospective reports). Thus, the generalizability of the results and applicability of the conclusions are minimized (Schubiner et al. 1993; Shakoor and Chalmers 1991; Schwab-Stone et al. 1999). Research in this area has been largely cross-sectional, with few studies examining the longitudinal and developmental effects of exposure to violence over time (DuRant et al. 1994). This limits the ability to determine causality and identify variables that may mediate the association between community violence exposure and adjustment (CooleyQuille et al. 1995). Furthermore, much of the extant research has focused on small or highly selected samples (e.g., juvenile delinquents, high-risk males), used nonstandardized or noncomparable measures of community violence, and lacked a solid theoretical foundation.

Gorman-Smith and Tolan (1998) recommended that the impact of violence exposure is investigated among youth residing in different neighborhoods and communities. The MORE Project was designed to determine the prevalence of total community violence exposure among children at varying levels of risk for exposure. It compares several neighborhood strata within the same city that represent different levels (low, moderate, and high) of violent crime and associated risk for exposure to chronic community violence. It includes different modes of exposure to community violence (i.e., media, reported, witnessed, victim, and war/terrorism), as well as violence perpetration, and interparental conflict. Significant features of this study are its prospective longitudinal (three annual waves) design; child, parent/guardian, and teacher interviews; and focus on youth at-risk for varying levels of exposure to community violence. Measurement methods permit the investigation of a proposed conceptual model of the emotional, behavioral, substance use, and academic effects of community violence exposure on youth. Additionally, the selected setting for this project is significant because of the wide range in rates of neighborhood crimes which are known to be associated with children's exposure to community violence (Selner-O’Hagan et al. 1998).

\section{Violence in Baltimore City}

Baltimore, Maryland is an optimal city in which to study the epidemic of community violence and its impact on children and families. At the community level, some Baltimore neighborhoods have maintained extremely low crime rates whereas others have chronically high rates making it an ideal setting for a community epidemiological study of exposure to community violence. In 2006, there were 276 homicides and 10,816 violent crimes in this city of over 600,000 residents (Federal Bureau of Investigation 2006a). This reflects a significant decrease from the recordhigh of over 350 homicides 15 years ago (Dao 2005), consistent with a national trend in reduced rates (Federal Bureau of Investigation (FBI) 2002). However, the homicide rate in Baltimore remains nearly seven times the national rate, six times the rate of New York City, and three times the rate of Los Angeles (FBI 2006b). Although crime in Baltimore is considered severe, police officials have highlighted that most violent crimes, particularly homicides, are committed by people who know their victims and who are often associated with drug-trafficking (FBI 2006b). For example, Baltimore has more heroin addicts and heroin-related crime than any other city in America (Drug Enforcement Administration 2008). This, however, is little consolation to children who reside within and visit the neighborhoods in which the violence occurs.

\section{Community Violence}

Over $80 \%$ of children living in urban areas have witnessed community violence; as many of $70 \%$ of them report being victims of this violence (Fitzpatrick and Boldizar 1993; Gladstein et al. 1992; Kliewer et al. 1998). Culture plays a role in the level of community violence to which youth are exposed (Cooley et al. 1995). Although a national phenomenon, violence is particularly acute in urban neighborhoods (e.g., Gladstein et al. 1992; Richters and Martinez 1993). Community violence is defined as deliberate acts intended to cause physical harm against a person or persons in the community (Cooley-Quille et al. 1995). Although the 
direct victims are obvious, its indirect victims are far more numerous. They are affected because they are: bystanders, witnesses or familiar with victims, or are cognizant of or anxious about the potential for violence (Horn and Trickett 1998; Lorion 1998). Chronic community violence is widespread among settings or social groups; its consequences impact significant portions of the community over a substantial period of time (Lorion 1998). Youth living in innercities are exposed to more violence than those living in middle- to upper-SES neighborhoods (Gladstein et al. 1992). Youth living in areas with the highest crime rates report the most violence exposure; they are also in the city's poorest neighborhoods (Selner-O'Hagan et al. 1998). Although higher crime rates increase the likelihood of direct exposure to community violence, exposure occurs through various modalities (media, witness, hearsay, victimization, war/terrorism) and extends beyond urban centers.

Community violence affects all racial and ethnic groups (Cooley-Quille et al. 1995); however, ethnic minorityespecially African American-children are disproportionately affected (Bureau of Justice Statistics 1991; Christofel 1990; Jenkins and Bell 1994; Selner-O'Hagan et al. 1998). This increased exposure may be a function of socio-economic status and community variation given that ethnic minorities are over represented in urban areas (Attar and Guerra 1994; Cooley-Quille et al. 1995; Rosenberg et al. 1992). Nationally, African American residents in innercities experience a higher rate of violent crime than urban Caucasians. African Americans are also victims of violence at rates higher than Caucasians (i.e., 99 per 1,000 vs. 61 per 1,000, respectively; Smith et al. 1999). Among a nationally representative sample of adolescents, $57 \%$ of the African American children had witnessed violence compared to $50 \%$ of the Latinos and $34 \%$ of the Caucasians (Crouch et al. 2000). African American youth's exposure to violence (witness, victim) did not decrease with higher family incomes, as it did for Caucasians (Crouch et al. 2000). Given their disproportionate exposure, African Americans should be directly studied when investigating community violence. Important to examine is whether higher socioeconomic status protects African Americans against exposure; currently, the literature is mixed.

There are several types of community violence. The form that has been researched the longest is media violence. The form of exposure to community violence that has received the most recent attention in the United States is war/terrorism or "world" violence. The media coverage of the official Iraq war provided American familiesincluding children-the experience of war in real time. They were likely the first generation of American children to experience war so intimately. Researchers have suggested that there is a dosage effect regarding children's exposure to violence in the media; the more exposure through television, the more post-traumatic stress symptoms they experience (Pfefferbaum et al. 2001). Moreover, television violence may serve to sustain those anxiety symptoms (Pfefferbaum et al. 2001). Children may be affected by war or terrorism not only through the media, but also by disruptions or changes in their regular routines at school and in other activities (Stuber et al. 2002). Additionally, knowing or seeing an adult who has been upset or affected about an attack may affect children (Stuber et al. 2002), such as relatives in active military duty or recently discharged. The question remains: What is the impact of war/terrorism on the emotional, behavioral, and academic functioning of American children? Shaw (2003) conducted a review of potential outcomes on children not just in the United States, but also the world. This question is difficult to answer for American youth, as there are likely cohort effects. For example, following the terrorist attacks in 2001 against the World Trade Center in New York City and the Pentagon in Washington, DC, American children of varying ages were widely exposed to "world" violence, followed by the anthrax attacks through the US postal system, and later initiation of Operation Iraqi Freedom in 2003. These events exposed American youth to world violence not only through the media (e.g., news reports), but also through hearsay from military personnel (e.g., friends, relatives). Over the past half decade or more, American youth's exposure to "real" (versus fictitious film, television, and videogame) world violence has become less salient, despite ongoing military operations in the Middle East and worldwide.

A review of ten studies (over 5,000 inner city children) indicated that a minimum of $40 \%$ (range $=25-70 \%$ ) of the children reported witnessing a shooting (Jenkins 2001). Often, the victims of these severe forms of community violence are friends or family members. Caregivers in our research projects have even stated that they do not watch local television news, nor do they allow their children to do so for fear of hearing reports of harm befalling a family member or acquaintance. Studies in Chicago schools indicate that over $70 \%$ of the shooting incidents youth witnessed involved a friend or family member as the victim; about $10 \%$ were a sibling or a parent (Jenkins and Bell 1994; Uehara et al. 1996). Not only is the severity of urban children's exposure to community violence significant, so is the chronicity. Multiple studies have found that African American youth are frequently exposed to chronic and severe community violence (e.g., Hinton-Nelson et al. 1996; Jenkins and Bell 1994), as opposed to that which is episodic or single, nonrecurring events. Furthermore, not only are these youth often chronically exposed to community violence, but other forms of violence as well (e.g., intrafamilial violence; Crouch et al. 2000; Hampton et al. 1989). 
The long-term, cumulative effects of chronic exposure to community - and other forms of-violence should be conducted in middle childhood and into adolescence to determine the impact on youth's development in numerous domains. Involving multiple informants and methods to assess youth's exposure to community violence improves upon the field's reliance on single sources of data, most typically the child's self-report. Parent-child agreement on reports of community violence exposure has been poor (Richters and Martinez 1993). Youth's self-reports of violence exposure are consistently higher than reports from other informants (Ladd and Kochenderfer-Ladd 2002; Schwartz and Gorman 2003; Selner-O'Hagan et al. 1998), including community violence exposure as reported by children compared to their parents (e.g., Cooley-Strickland et al. 2009). However, it is unclear which is the most valid report given the field's assumption that youth are best informed about their own experiences with violence (Richters and Martinez 1993; Schwarz 1999) and that it may be the perception of the frequency and severity of violence that most substantially influences the subsequent impact of that exposure.

\section{Exposure to Community Violence and Emotional, Social, and Behavioral Functioning}

Stress theory has been primarily used as the theoretical foundation to investigate the emotional and behavioral effects of children's exposure to community violence (Horn and Trickett 1998). Typically, community violence is the identified stressor and is used to predict maladaptive outcomes. Chronic exposure to community violence is believed to have a negative impact on various aspects of youth's development and adaptive functioning (Attar and Guerra 1994; Fitzpatrick and Boldizar 1993; Jenkins and Bell 1994; Martinez and Richters 1993). Youth growing up in urban environments with high levels of poverty, overcrowding, and violence show a wide range of maladaptive outcomes, including internalizing symptoms such as anxiety, post-traumatic stress symptoms, depression, academic failure, and school disengagement (Gibbs 1984; Lorion et al. 1999; Myers et al. 1992; Osofsky et al. 1993; Singer et al. 1995). Youth with higher levels of exposure to community violence (via incidence and/or severity) report significantly more distress than those with lower exposure (Fitzpatrick and Boldizar 1993; Freeman et al. 1993; Jenkins 1993; Martinez and Richters 1993).

Collectively, the evidence suggests that children's exposure to community violence increases the likelihood of developing internalizing symptoms (e.g., Fitzpatrick 1993; Fitzpatrick and Boldizar 1993; Hutcheson 1998; Martinez and Richters 1993), although there have been studies that have not found a significant positive relationship (e.g., Hill and Madhere 1995; Kubiak 1998; White et al. 1998). Reviews of the literature generally conclude that when the data are from the same source, there is a positive linear relationship between anxiety/internalizing symptoms and children's exposure to violence (Horn and Trickett 1998) such that the greater the exposure, the more problematic the outcome (e.g., Pynoos et al. 1987; Hutcheson 1998).

Poor urban youth are at-risk for a range of co-occurring emotional and behavioral symptoms and poor psychosocial functioning; disruptive behavior problems (Gorman-Smith and Tolan 1998) and aggression are central features (Tolan and Henry 1996). The community violence exposure of African American and Hispanic male children has been linked with increased aggressive behavior (Gorman-Smith and Tolan 1998). Witnessing and being the victim of violence in the community serves as a risk factor for future aggression (Attar and Guerra 1994; Bandura et al. 1961; Cooley-Quille et al. 2001; DuRant et al. 1994; Kubiak 1998). Complicating the directionality of the relationship is research that has shown that exposure to community violence may exacerbate externalizing behavior characteristics (Gorman-Smith and Tolan 1998).

Schwab-Stone and colleagues (1999) examined violence exposure in a community-based longitudinal study and found that violence exposure was associated with externalizing behavior and internalizing symptoms across gender and ethnic groups. Co-occurrence of psychiatric syndromes may represent shared underlying pathogenesis (Tolan and Henry 1996). Horn and Trickett (1998) concluded that it may not be a contradiction that children's exposure to violence is related to externalizing (aggression) and internalizing (anxiety and affective) behavior problems; both can be true. Although there are conflicting results (e.g., Loeber and Keenan 1994), the literature suggests that youth with co-morbid anxiety and aggression may be at greater risk for impairment than youth who have either anxious symptoms or aggressive behaviors (e.g., Boivin and Vitaro 1995; Ialongo et al. 1996; Kashani et al. 1991; Ladd and Burgess 1999). Childhood anxiety may be an important risk factor for aggression given that anxious children perceive ambiguous situations in more threatening and hostile ways than nonanxious children (Kashani et al. 1991). This finding is also consistent with social information processing theory (Crick and Dodge 1994; Dodge 1985, 1986), which posits that a series of biases in the processing of social information in ambiguous situations can trigger aggressive behavior.

Researchers are increasingly interested in social-cognitive factors which may mediate the association between exposure to community violence during childhood and aggressive behavior (Bradshaw and Garbarino 2004; $\mathrm{Gu}$ erra et al. 2003). Several studies have shown that aggressive children tend to be hypersensitive to cues of threat, 
selectively attend to aggressive cues, and overlook other situational factors that may have influenced the person's behavior (for reviews see Crick and Dodge 1994; Dodge and Pettit 2003). Aggressive children are believed to have a hostile attribution bias, which influences their interpretation of the situation, such that they infer greater hostility in other people's ambiguous behavior. They may have a large repertoire of aggressive responses that can be enacted, and believe aggressive responses are more effective at obtaining the desired goal than prosocial ones. Consistent with social learning theory (Bandura 1973), witnessing violence may model aggression as an effective, normative, and justified way of resolving conflict or obtaining desired goals. Aggressive youth tend to perceive their own aggressive behavior as the proper defense against others' hostile intent (Dodge and Somberg 1987).

Other researchers have suggested that problems regulating emotions also play a role in increasing the risk for maladaptive coping and aggressive behavior among children who witness violence (Mushe-Eizenman et al. 2004). Poor emotion regulation may contribute to poor processing of social cues and impulsive, aggressive behavior in ambiguous and potentially conflictual situations. Therefore, it is important to examine the relationship between negatively biased social information processing, coping, and emotion regulation as possible factors mediating the association between community violence exposure and aggressive behavior. Having an enhanced understanding of the factors that mediate the association between community violence exposure and aggressive and academic outcomes would inform the development of preventive interventions that target relevant social-cognitive mediators.

\section{Children's Exposure to Community Violence and Academic and Cognitive Functioning}

Not well researched are the cognitive, academic achievement, and educational effects of violence exposure on children (Osofsky 1995). Studies of the impact of community violence on children's school functioning are necessary and meritorious, yet there is a paucity of empirical investigations that directly assess academic functioning (Schwartz and Gorman 2003). Included among the few available studies are those that assess perceived academic functioning (e.g., Bowen and Bowen 1999; Overstreet and Braun 1999; Schwab-Stone et al. 1995; Schwartz and Gorman 2003). It is believed that the distractions youth experience from exposure to community and school violence disrupt cognitive development (Horn and Trickett 1998). The long-term consequences are underexplored, although the dropout rates are near $50 \%$ for historically disadvantaged ethnic minority groups (Swanson 2004)—particularly those residents from urban areas with the highest levels of poverty and violence. It is increasingly understood from a life course perspective that dropping out of school is not an isolated event, but is a process that begins in early childhood and is impacted by cumulative factors (Alexander et al. 2001).

Community violence exposure has been associated with attentional impairment, declines in cognitive performance (Saltzman 1996; Singer et al. 1995) and declines in school achievement (Bell and Jenkins 1991). These academic difficulties have been suggested to result from lowered concentration levels due to distracting and intrusive thoughts concerning violent events that may accumulate over time and with repeated exposure (Bell 1997; Horn and Trickett 1998; Taylor et al. 1997), thus a meditational model is warranted (Schwartz and Gorman 2003). In a cross-sectional study of urban elementary school students, Schwartz and Gorman (2003) found support for such a model in that community violence was associated with poor academic performance as mediated by depressive symptoms and disruptive behavior. The authors suggest that community violence exposure may interfere with children's developing capacities for self-regulation and behavioral control (Schwartz and Gorman 2003), which is consistent with the literature on social information processing (Dodge and Pettit 2003). Gender also may introduce an interaction effect given that inner-city girls who have been traumatized by violence are more likely to be suspended from school and arrested (Lipsitz et al. 2000).

When youth's caregivers experience significant stressors-as is typical among those who dwell in high crime neighborhoods-they are less able to assist in their children's cognitive and social development which is important in negotiating their children's academic success. Research conducted by the first author has shown a positive relationship between neighborhood violence and school removal (i.e., school suspensions, expulsions; e.g., Boyd et al. 2003). As the primary developmental task for children is academic success, it is important to directly investigate the impact of community violence on children's academic performance.

\section{Community Violence: Age and Developmental Differences}

In communities that frequently experience violent crime, reports (percentages and incidents) of witnessing violence increase with the average age of the children (Horn and Trickett 1998). Thus, the longer they reside in the neighborhoods, the more likely they will be repeatedly exposed to violence; hence the characterization of r"chronically" violent communities (Hill and Madhere 
1995). Of particular concern are findings indicating that children are exposed to severe and chronic community violence at young ages (Attar and Guerra 1994; Federal Bureau of Investigation (FBI) 1993; Gladstein et al. 1992). For example, first and second grade children reported exposure to community violence at levels similar to that of fifth and sixth graders; the young children had also witnessed high levels of violence before they entered elementary school (Richters and Martinez 1993). Witnessing violence as young children (3- to 5-year olds) was a risk factor for behavior problems (Shahinfar et al. 2000). Compounding the problem, caregivers consistently underestimate the frequency of their children's exposure to violence and thereby are believed to be less able to protect them (Cooley et al. 2004; Richters and Martinez 1993). Research suggests that young children's —as well as their caregivers'-exposure to community violence is a significant risk factor for maladaptive development (Osofsky 1995; Scheeringa and Zeanah 1995). For example, Linares et al. (2001) found support for a meditational model of the impact of maternal distress (general distress, PTSD symptoms) on the association between community violence exposure and their young children's internalizing and externalizing behavior problems. Aisenberg and Ell (2005) found similar results and concluded that community violence research should move beyond an individual child focus to a more integrated child, parent, family, community approach to appropriately contextualize the effects of exposure and subsequent mental health prevention and intervention. Clearly, investigation of more comprehensive mediational models (parental/family distress affecting children's behavior) is warranted.

Young adolescents may be more vulnerable to adverse outcomes associated with violence exposure than older adolescents (Schwab-Stone et al. 1999), but there may be heightened vulnerability at even younger ages. Because adolescents between the ages of 12 and 15 are victims of crime more frequently than any other childhood age group (Jenkins 2001), it is important to conduct prospective studies of the emotional, behavioral, and academic impact of exposure to violence in youth preceding that critical period of heightened victimization. To this end, middle childhood is an important developmental period to begin a longitudinal study. Middle childhood is also when negative academic patterns become fixed and stable (Pungello et al. 1996 as cited in Schwartz and Gorman 2003).

\section{Community Violence: Gender Differences}

Males generally report more community violence exposure than females (Selner-O'Hagan et al. 1998). For example, older boys report witnessing more frequent and severe violent events than girls (Schubiner et al. 1993; Singer et al. 1995; Jenkins and Bell 1994). However, there are exceptions such that no gender differences have been found in some studies (Attar et al. 1994; Farrell and Bruce 1997; Uehara et al. 1996). There are also conflicting reports of whether there are gender differences in children's emotional and behavioral reactions to violence exposure. Two studies found that both sexes exhibited similar numbers of post-traumatic stress symptoms following exposure to violent acts (Pynoos et al. 1987; Schwarz and Kowalski 1991). Studies have shown that girls report more internalizing (anxiety, depression, and general emotional distress) symptoms associated with exposure than boys (Farrell and Bruce 1997; Fitzpatrick and Boldizar 1993; Jenkins and Bell 1994). However, there were no sex differences in emotional outcomes for older children (Martinez and Richters 1993).

An increasing pattern in community violence research has yielded reports that girls may be vulnerable to both internalizing and externalizing behaviors. For example, a study of sixth grade students showed that witnessing violence was predictive of girls' externalizing, but not internalizing, behavior (Farrell and Bruce 1997). Another study of urban, primarily African American children found that among girls, community violence exposure was significantly related to different forms of anxiety, but not among boys (White et al. 1998). Although there are clear age differences in youth's exposure to community violence, the impact of gender is less clear. There are likely interaction effects.

\section{Community Violence and Youth: Protective Factors}

Research on the effects of children's exposure to community violence has primarily focused on risk, not protective, factors. In general, it is the combination of risk factors that predicts which children will develop adverse functioning more so than the presence of any single factor, which follows the adversity index model (Rutter 1990; Rutter and Quinton 1977; Sameroff et al. 1998). However, it is known that some youth exposed to community violence have extraordinary coping skills (Fitzpatrick and Boldizar 1993). Despite experiencing similar levels of risk and vulnerability, differential outcomes-including resiliency-suggest that protective factors function to attenuate the effects of trauma (Rutter 1987; Garmezy 1993). These are factors that directly affect behavior, but also moderate the relationship between risk and healthier outcomes (Jessor et al. 1995). Tolan et al. (1997) discuss the unique styles of coping that children living in inner-cities must develop in their attempts to "stay out of harm's way." However, Tolan and colleagues stress the importance of 
distinguishing between "adaptive" and "effective" coping. In our research, we have found that the former pertains to coping styles that serve the child's immediate situational needs, but may not be prosocial and perhaps are even antisocial (e.g., physically fighting or stealing to "solve" a problem). Effective coping involves prosocial means that effect positive change, particularly over the long-term and in larger society.

More traditional conceptualizations of protective factors from the trauma literature that apply to community violence include pre-morbid emotional health and adjustment prior to exposure, highly functioning parents, and good family relations (Pynoos 1993; Pynoos et al. 1999). Family environment (e.g., communication, bonding, and warmth) and family support are protective for youth exposed to family violence (Boney-McCoy and Finkelhor 1995; GormanSmith and Tolan 1998), but also may be considered general protective factors, as are intelligence, school involvement, participation in activities outside the home, religion, and self-competence (Beardslee and Podorefsky 1988; LaGreca et al. 1998; Luthar et al. 2000; Resnick et al. 1997; Tiet et al. 1998). The impact of a supportive school environment (e.g., competent, qualified teachers, safe schools, safe classrooms) may also serve a protective role among children exposed to community violence. Interestingly, youth may experience numerous risk and protective factors simultaneously (Jessor et al. 1995). Perhaps the combination may inform why some youth develop in relatively healthy ways whereas others evidence significant emotional, behavioral, and/or academic adversity.

Despite recognition of the maladaptive consequences associated with exposure to community violence, there is limited research examining combined risk and protective factors associated with children's community violence exposure (Boyd et al. 2003). A longitudinal study that investigated whether individual level characteristics protected children from community violence exposure showed that among aggressive boys, low levels of anxiety protected them from later exposure (Boyd et al. 2003). More research is needed to gain a better understanding of the protective and risk mechanisms related to community violence exposure. For example, prosocial activities may be protective in nature because they decrease the opportunities for interacting with deviant peers, provide social support, and enhance self-competence. Relatedly, children's wellbeing suffers most greatly among those with lower levels of social support or higher social strain (defined as those without social networks that facilitate talking about violence; Kliewer et al. 1998). Youth need more support than adults because they are less skilled at expressing their trauma-related concerns and have fewer informal and formal sources of support and psychological coping (Kliewer et al. 1998).
An additional protective factor may be internal strength manifested by religious beliefs and practices. Some attention has focused on links between participation in religious and/or spiritual activities and physical and mental health (Dossey 1993; Koenig 1997). Studies generally show that religion and spirituality are modestly related to emotional well-being (Ellison 1991). Various mechanisms have been proposed to explain this relationship, such as religious/ spiritual involvement providing: meaning or purpose in life; inner-peace; connection to others and a community (Walters and Bennett 2000). Exploring the associated risk and protective factors is critical to advance the field from epidemiology into treatment and prevention.

\section{Community Violence and Youth and Anxiety}

Post-traumatic stress disorder (PTSD) is the most widely recognized anxiety disorder that has physiological concomitants, although all anxiety disorders affect physiological, behavioral, and cognitive response systems (Kendall and Hammen 1995). Considering each of these domains is important to understand the cause of PTSD (Jones and Barlow 1990) and other anxiety and internalizing symptoms. Post-traumatic stress symptoms may be used to illustrate the link between community violence and anxiety because the onset of PTSD is necessarily preceded by an external stressor. Previous research supports the relationship between symptoms of PTSD and youth's exposure to community violence (Pynoos et al. 1987; Schwarz and Kowalski 1991). Exposure to the external trauma causes exaggerated neurotransmitter activity and is related to aggression, hypersensitivity (Turner et al. 1997), and physiological and subjective hyperarousal (Keane et al. 1988). Biological factors are involved but cannot solely explain why some people develop PTSD after being exposed to traumas and others do not (Turner et al. 1997). Early studies found that adolescents living in inner-cities have higher blood pressures than youth living in suburban or rural areas (Thomas and Groer 1986), independent of race (Burns et al. 1980). Urban living is described as less esthetically pleasing, noisier, and more crowded (Thomas and Groer 1986). Interestingly, one study we conducted found that older urban adolescents with very high levels of exposure to community violence had lower resting blood pressures than lower exposed youth (A-Quille and Lorion 1999).

It is possible that older youth who are chronically and repeatedly exposed to violent events habituate or become desensitized (Fitzpatrick and Boldizar 1993). For example, signs of danger (e.g., police and ambulance sirens, gun shots) may occur with such frequency that youth eventually learn not to react with a "fight or flight" response and 
habituate to fear. In contrast, younger or infrequently exposed youth escape/avoid the anxiety-producing stimuli, a pattern that functions to increase or sustain the intensity of the fear response (Turner et al. 1997). The habituation or extinction model of fear is supported by a considerable body of literature noting that prolonged contact with fearproducing stimuli results in increased physiological reactivity and subjective distress. With repeated exposure, the physiological reactivity and anxious distress are followed by decreases in arousal and fear (i.e., the response habituates or is extinguished; Mowrer 1960). The concern is whether children in environments with high levels of community violence are learning to become desensitized to the signs of danger, but are not learning prosocial coping skills for managing their distress.

Some fears are developmentally inappropriate under almost all circumstances (Leonard et al. 1990), whereas others are adaptive or protective (Marks 1987). Anxiety clinicians and researchers have to differentiate between pathological anxiety and normal developmental fear (March and Parker 1999). The fears and anxiety associated with living in inner-city communities characterized by poverty, violence, and limited resources pose a challenge for determining whether the fears are reasonable or adaptive. Anecdotal reports by children living in inner-cities yield pervasive fears of being harmed (e.g., kidnapped, shot); their fears are even greater regarding harm befalling their family members (Cooley et al. 2004). Some meet threshold criteria for separation anxiety disorder (SAD), although they are older than the typical SAD child. Constant worry about one's own or loved ones' safety or health likely interferes with inner-city children's ability to function in developmentally appropriate, academically successful, and healthy ways (Cooley et al. 2004).

African American children rarely receive treatment for anxiety problems (Neal and Brown 1994). Epidemiological data on racial differences in childhood anxiety suggests that African American children have higher rates than Caucasian youth (Kashani and Orvaschel 1988; Neal and Turner 1991). Compared to Caucasian children, African American children report more fears; those fears appear to be more reality-based (Nalven 1970) and relatively more stable. The racial differences in children's fears persist even after controlling for socio-economic status and age (Last and Perrin 1993). Older children's fears are more socio-evaluatively based (Morris and Kratochwill 1983) and center around harm befalling self or a family member (Neal and Brown 1994). Inter-racial regional differences have also been found such that northern urban African American children report more fears than southern rural children (Neal and Baskett 1993). As such, African American children from low-socio-economic status backgrounds who live in violent, urban communities may be at even greater risk.
Community Violence and Youth: Depressive Symptoms

Depression is a significant problem across racial, ethnic, and socioeconomic groups, but it is most prevalent among those with low socioeconomic status (Beardslee 2003). Ethnic minorities are over-represented in lower socio-economic status groups (Bruce et al. 1991). Poor urban children are among those most vulnerable to the development of internalizing and externalizing behavior problems (McKay et al. 1998; Tolan and Henry 1996). Elementary school students may experience adult like depressive symptoms and disorders (Weisz et al. 1987). Investigators have found moderately strong associations between children's exposure to community violence exposure and depressive symptoms, including intrusive thoughts, low energy, and diminished motivation (Osofsky 1995; Schwartz and Gorman 2003).

Depression is a disorder that should be understood from several different perspectives: It is a biological disorder, but one that profoundly affects family functioning and relationships; etiological factors are both genetic and environmental (Beardslee 2003). Children of parents with mood disorders are two to four times more likely to develop mood disorders compared to children in families without parental illness; depression rates as high as 50\% have been found among adolescents and young adults who have severely ill parents (Beardslee 1998). Other significant potential factors in the development and maintenance of depression include: adverse life events; racism and prejudice, however covertly experienced by ethnic/racial minorities; and poverty (e.g., Beardslee 2003; Brown et al. 1995; Koss-Chiono and Vargas 1992; Turner and Lloyd 1999). Ethnic minority children living in poor urban environments are at risk for experiencing chronic levels of neighborhood violence (Barreto and McManus 1997) and their parents/caregivers may limit their activities outside of the home in an attempt to protect them harm (McAlisterGroves et al. 1993). However, social withdrawal is associated with depression and other internalizing symptoms so these restrictions may thwart children's emotional development (Beardslee 2003) and physical health and increase their vulnerability to depression and other affective problems.

Depressive symptoms may also occur because of environmental adversity, like being a victim of violence, bereavement, or having multiple first-degree relatives with the disorder (Beardslee 2003). Other risk factors are low self-esteem, hopelessness, helplessness, being female, and poverty (Institute of Medicine 1994). Youth's exposure to community violence has been linked to symptoms of distress (e.g., Kliewer et al. 1998; Martinez and Richters 1993) but the form of distress may be related to the type of violence youth experience (Cooley-Quille et al. 1995; McAlister-Groves et al. 1993). For example, children's 
exposure to acute (i.e., nonrecurring) forms of community violence may be related to internal distress (e.g., anxious, depressive, somatic, and withdrawal symptoms), whereas exposure to chronic community violence may be related to externalizing behaviors (e.g., aggression, conduct problems; Cooley-Quille et al. 1995). This differential outcome may be a function of vicarious learning such that witnessing high levels of community violence models aggressive and externalizing behaviors (Cooley-Quille et al. 1995). However, alternative explanations include the behavioral principles of reinforcement and punishment. Specifically, internalizing symptoms (e.g., depression, anxiety, withdrawal, somatic complaints) may not be accepted (i.e., are punished) among those dwelling in highly violent communities because they are perceived as weaknesses, thus making youth vulnerable and easy targets for future victimization (Earls 1991; Barreto and McManus 1997).

\section{Community Violence and Youth: Substance Use}

Prevalence rates for drug use initiation by race/ethnicity indicate that while African Americans are less likely than Caucasians to initiate smoking tobacco and drinking by 13 years of age, they are at greater risk for initiating cocaine and marijuana use at earlier ages (Everett et al. 1998). Prevalence data for early-onset substance abuse is rare. Nonetheless, there are limited descriptive statistics for substance use and progression. For example, Wills et al. (2001) studied elementary school children in a mixed urban-suburban community (mean age 11.8 years; $27 \%$ African American). About one-quarter (24\%) of the children had tried one or two cigarettes and $1 \%$ indicated smoking on at least a monthly basis. For alcohol use, almost one-third $(30 \%)$ of the elementary school students reported drinking alcohol one or two times, and $2 \%$ drank on at least a monthly basis. Regarding marijuana, $2 \%$ had tried it once or twice, and less than $1 \%$ reported using it regularly (Wills et al. 2001). Another study examined the prevalence of alcohol and drug use among children in three cities: Denver, Pittsburgh, and Rochester (Huizinga et al. 1993). The authors found a high frequency of drug initiation prior to the teenage years. Denver's rates represented the highest-risk areas; for 7-year-old children: $15.3 \%$ of the boys and $9.7 \%$ of the girls reported having drank alcohol at least once, while $1.2 \%$ of the boys and $0.7 \%$ of 7 -year-old girls reported having smoked marijuana one or more times (Huizinga et al. 1993).

In a preliminary study conducted by the first author in which inner-city children's coping styles were assessed, fifth grade African American students reported using substances when they were "faced with difficulties or felt tense." Almost one-quarter $(22.9 \%)$ of the 11 - and 12-year olds reported having smoked tobacco and $17.1 \%$ reported drinking alcohol at least sometimes to help them "cope." Research investigating the outcomes associated with community violence exposure should target substance use. Children may not consider themselves "substance users" out of context (e.g., not associated with peers or distress). An advantage of studying middle childhood over time permits the identification of mediating and moderating variables that influence initiation and maintenance of drug use.

Trauma has been related to adolescent substance abuse (Kilpatrick et al. 2000). Several studies have shown that post-traumatic stress is a risk factor for the development and chronicity of depression and substance use (Bolton et al. 2000; Giaconia and Reinherz 1995; Kilpatrick et al. 2000). Behavior problems (e.g., aggression, unsafe behaviors) are associated with drug use initiation (Epstein et al. 2000). A comprehensive summary of possible causes of the association between substance use and violence was presented by Mulvey and colleagues (Mulvey et al. 2006): (1) Substance use causes violence either directly (e.g., via disinhibition) or indirectly (e.g., mediated by association with aggressive peers; poor coping skills; life stressors); (2) Experience with violence increases the likelihood of using substances (e.g., substance use as a coping response); or (3) The relationship is spurious (i.e., a tertiary factor enhances the exhibition of substance use and/or aggression) (Parker and Auerhahn 1998; White 1990, 1997).

Developmental patterns of drug use may vary with age, gender, ethnicity, social class, and ecological, cultural, and historical conditions (Kandel et al. 1978). Certain risk factors for drug initiation exert differential effects according to gender and ethnicity (Brunswick and Messeri 1984; Ellickson and Morton 1999). Regarding urban African American youth, variables from multiple domains (e.g., personal background, school achievement, familypeer orientations, psychogenic orientations, health attitudes, and behaviors) have been shown to influence smoking initiation (Brunswick and Messeri 1984). However, the only predictors of African American youth's "hard" drug use were social influences promoting drug use and intentions to use them (Ellickson and Morton 1999).

The directionality of the association between substance use and poor school performance is uncertain (Bryant et al. 2000). Investigators found that among 8th to 12th grade students, adverse school experiences (i.e., school misbehavior, poor academic achievement) precipitated tobacco use (Bryant et al. 2000). Another study found similar results among African Americans; those who dropped out of school were more likely to inject drugs as adults (Obot and Anthony 2000). However, another study did not find that poor grades predicted substance (i.e., inhalant) use for African American high school students, but they did for Asians (Mackesy-Amiti and Fendrich 2000). Importantly, 
researchers recommend that the relations between youth's problem behaviors (e.g., academic failure, deviance, alcohol, and marijuana use) are assessed as they change over time, particularly identifying the risk and protective factors that influence the undesired behaviors (Duncan et al. 2000).

\section{The MORE Project Study Questions}

There are five main questions that are being investigated in the MORE Project. They are: (1) What is the prevalence of urban children's exposure to community violence? (2) What are the risk factors associated with children's exposure to community violence? (3) What are the protective factors associated with preventing children's exposure to community violence? (4) What are the adverse outcomes associated with children's exposure to community violence? (5) What factors protect against the adverse outcomes of children's community violence exposure? Each main question will be furthered examined by: Stratum of neighborhood violence (low versus moderate versus high strata or by low and moderate versus high); gender; age; and, when appropriate, informant (child, parent, and teacher).

The conceptual model that provides the foundation for the MORE Project is illustrated schematically in Fig. 1.
Figure 2 identifies the major constructs assessed in the project that correspond to the main questions under investigation.

\section{Method}

Sample and Procedures

\section{Sampling Design}

Neighborhood crime is hypothesized to place youth at risk for exposure to community violence, as has been found in previous studies (e.g., Selner-O'Hagan et al. 1998). There are a total of 55 neighborhoods that link to Baltimore City Public Schools using data provided by the Baltimore City Data Collaborative (BCDC 2003) (http://www.baltimore kidsdata.org). The Data Collaborative compiles agency databases and other informational rosters from sources such as the Baltimore City Health Department, Baltimore City Public Schools, Baltimore Police Department, Maryland Department of Health and Mental Hygiene, and Baltimore City Child Care Resource Center. Community boundaries were drawn considering the city's neighborhood and community organizations and existing census tract boundaries to create statistical profiles. All 55 communities were rank

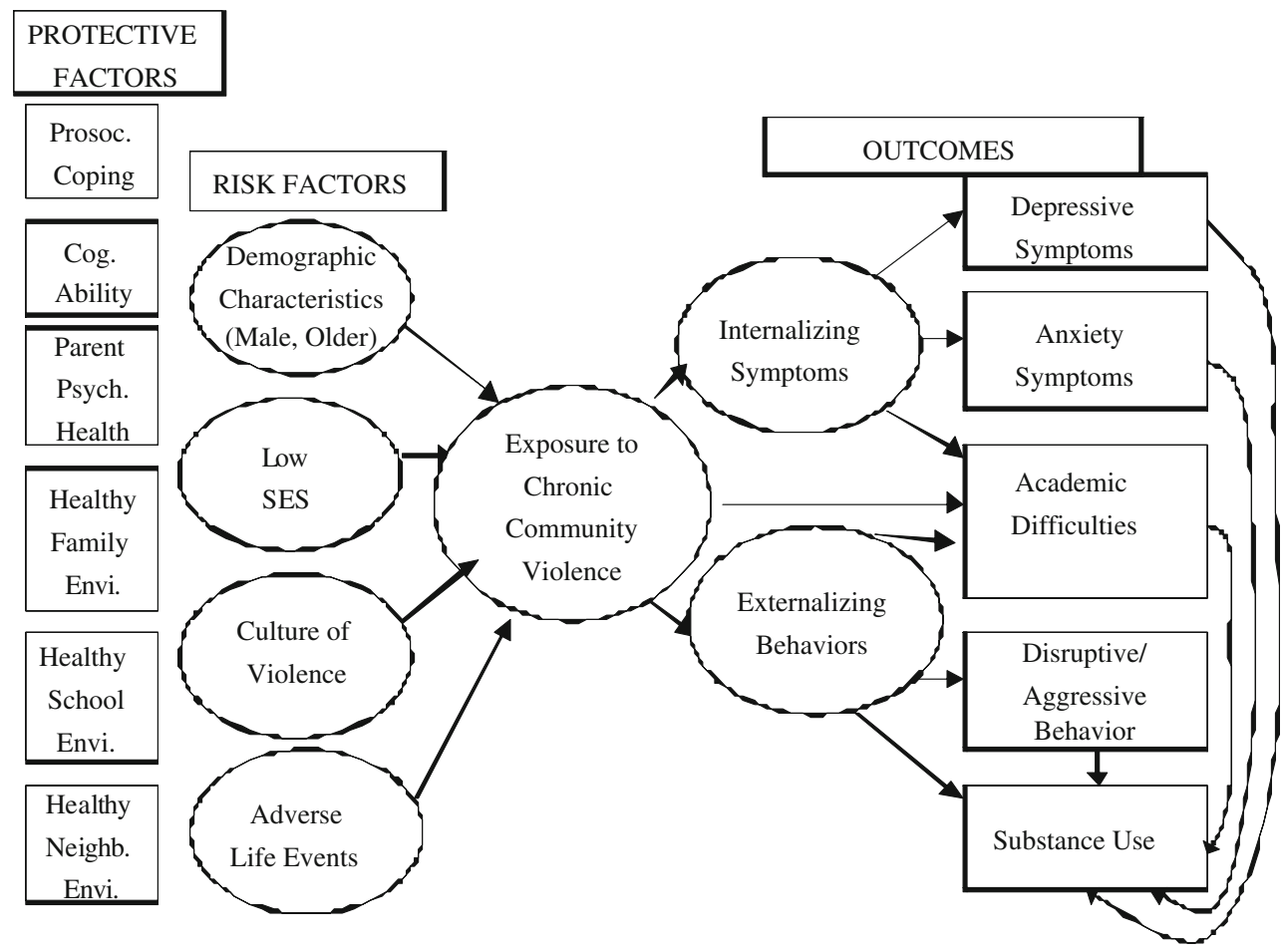

Fig. 1 Conceptual model of the effects of children's exposure to community violence. Prosoc. Coping prosocial coping; Parent Psych. Health parent psychiatric health; Cog. Ability cognition and cognitive ability; Healthy Family Envi. Healthy family environment; Healthy
School Envi. healthy school environment; Healthy Neighb. Envi. Healthy neighborhood environment; Low SES low socio-economic status 


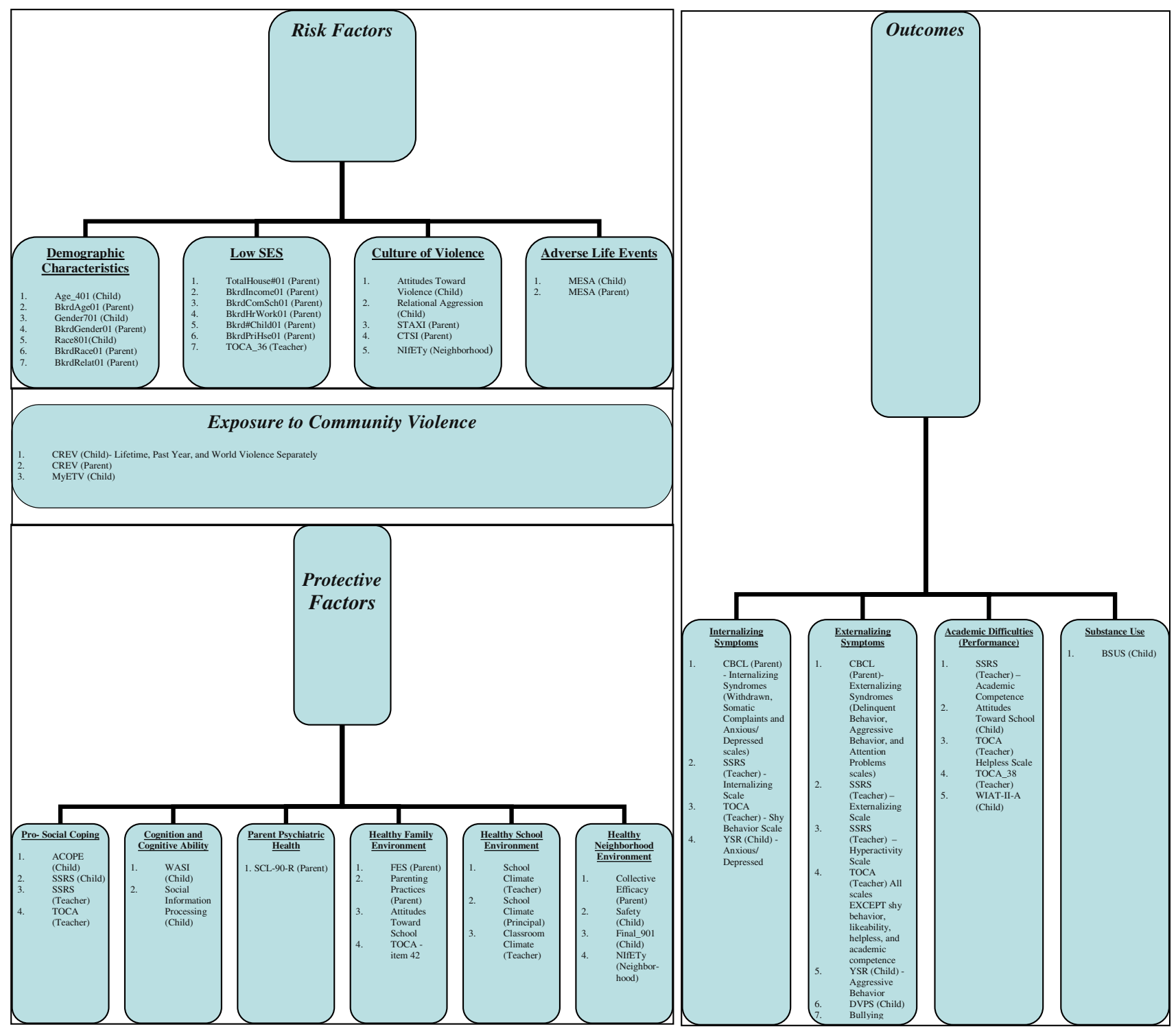

Fig. 2 Constructs assessed in the MORE Project and their associated factors

ordered from 1 to 55 based on their Baltimore City neighborhoods' homicide rates in 2002 (the most recent year for which data were available when the project was funded). Ten of those communities had zero homicides; the remaining 45 communities had between 1 and 164.3 homicides per 100,000 residents. The 10 neighborhoods with no homicides in that year were placed in the "low" neighborhood violence stratum (i.e., 0 homicides per 100,000 residents). The "moderate" violence stratum consisted of the four communities in the middle of the distribution of homicide rates (i.e., 25.0-31.4 homicides per 100,000 residents), and the four communities with the highest homicide rates (i.e., 97.2164.3 homicides per 100,000 residents) were placed into the "high" violence stratum. Within each stratum, the neighborhood with the two largest schools enrolling third through fifth graders became our target schools.

Once approval to conduct the MORE Project was obtained from the Johns Hopkins Bloomberg School of Public Health's Institutional Research Board and the Baltimore City Public School System, funding from the National Institute on Drug Abuse (NIDA) was awarded and a Certificate of Confidentiality from the Department of Health and Human Services was received. The principals at eight schools were contacted by the Project Investigator and/or Project Director to obtain their permission to partner together to conduct the MORE Project. Two principals declined, one in the high stratum reportedly because of his skepticism of research studies and feeling overburdened by 
current responsibilities, and the other from the moderate stratum who stated that it was her first year as principal and she did not have enough social capital among her school parents to ask them to participate in a research study. The elementary schools with the next largest student body in those neighborhood strata were contacted and their principals consented. A $\$ 1,000$ honorarium was presented to each participating school to thank them for partnering with the MORE Project and to defray associated expenses.

The two elementary schools in the MORE Project located in the high violence stratum are situated in one zip code, the two medium violence schools are located in another zip code, and the two low violence schools are in two other zip codes that have similar demographic characteristics within each stratum. Across strata, there are some differences. For example, ANOVAs indicate that the percentages of African American residents differ across the community strata $(p<.001)$, with fewer in the low and most in the high, which will need to be adjusted for in subsequent analyses. The population density for the low violence community is less than the other strata, but we will be unable to "control for density" since it is fully collinear with strata and it is one of the distinguishing characteristics of urban versus inner-city life. Table 1 characterizes differences between the three strata as categorized by their zip codes.

\section{Participants}

The MORE Project participants are comprised of 746 students, their parents/caregivers, and teachers. Recruitment spanned one and one-half academic years among 8- to 12-year-old students who attended six urban public elementary schools located in three Baltimore, Maryland

Table 1 Demographic characteristics of low, moderate, and high violence strata MORE Project neighborhoods in Baltimore City based on zip code

\begin{tabular}{|c|c|c|c|}
\hline & Low violence stratum & Moderate violence stratum & High violence stratum \\
\hline Zip code population (2000) & 21,285 & 55,059 & 41,636 \\
\hline Males & $10,061(47.3 \%)$ & $26,322(47.8 \%)$ & $19,101(45.9 \%)$ \\
\hline Females & $11,224(52.7 \%)$ & $28,737(52.2 \%)$ & $22,535(54.1 \%)$ \\
\hline Caucasians & $12,635(59.4 \%)$ & $13,810(25.1 \%)$ & $3,322(8 \%)$ \\
\hline African Americans & $7,815(36.7 \%)$ & $37,318(67.8 \%)$ & $37,372(89.8 \%)$ \\
\hline American Indians & $61(0.3 \%)$ & $146(0.3 \%)$ & $58(0.1 \%)$ \\
\hline Asian Americans & $249(1.2 \%)$ & $2,453(4.5 \%)$ & $329(0.8 \%)$ \\
\hline Native Hawaiians and Other Pacific Islanders & $5(0.02 \%)$ & $18(0.03 \%)$ & $16(0.04 \%)$ \\
\hline Other race/ethnicity & $151(.7 \%)$ & $323(.6 \%)$ & $93(.2 \%)$ \\
\hline Two or more races & $369(1.7 \%)$ & $991(1.8 \%)$ & $446(1.1 \%)$ \\
\hline Land area & 2.9 square miles & 4.3 square miles & 2.2 square miles \\
\hline Population density & 6,979 people per square mile & 11,860 people per square mile & 17,610 people per square mile \\
\hline Median resident age & 37.9 years & 31.8 years & 33.5 years \\
\hline Median household income (1999) & $\$ 43,723$ & $\$ 30,304$ & $\$ 20,637$ \\
\hline $\begin{array}{l}\text { Residents with income below the poverty } \\
\text { level in } 1999 \text { (State of Maryland: } 8.5 \% \text { ) }\end{array}$ & $7.6 \%$ & $23.4 \%$ & $35 \%$ \\
\hline $\begin{array}{l}\text { Residents with income below } 50 \% \text { of the } \\
\text { poverty level in } 1999 \text { (State of Maryland: } \\
4.2 \% \text { ) }\end{array}$ & $3.5 \%$ & $12.2 \%$ & $17.9 \%$ \\
\hline $\begin{array}{l}\text { Percentage that lived in the same house } 5 \text { years } \\
\text { ago }\end{array}$ & $63 \%$ & $52 \%$ & $54 \%$ \\
\hline Title 1 School (2007-2008) ${ }^{\mathrm{a}}$ & $\begin{array}{l}\mathrm{NO} \text {-neither participating } \\
\text { school }\end{array}$ & $\begin{array}{l}\text { NO_neither participating } \\
\text { school }\end{array}$ & $\begin{array}{l}\text { YES—both participating } \\
\text { schools }\end{array}$ \\
\hline Students in private schools: Grades $1-8$ & 960 & 884 & 369 \\
\hline Students in private schools Grades 9-12 & 268 & 308 & 200 \\
\hline Registered sex offenders (early 2007) & 20 & 110 & 109 \\
\hline Prevalence of HIV/AIDS ${ }^{\mathrm{b}}$ (Living cases) & 159 & 1,372 & 1,873 \\
\hline
\end{tabular}

http://www.city-data.com (2008)

a www.bcps.k12.md.us/School_Info/index.asp

b Maryland Department of Health and Mental Hygiene, AIDS Administration (2007). Baltimore City HIV/AIDS Epidemiological

Profile. www.dhmh.state.md.us/AIDS/ 
Table 2 Characteristics of the MORE Project total student sample by strata

\begin{tabular}{|c|c|c|c|c|}
\hline & $\begin{array}{l}\text { Entire second-fifth } \\
\text { grade sample }(n=746)\end{array}$ & $\begin{array}{l}\text { Low violence stratum } \\
(n=284)\end{array}$ & $\begin{array}{l}\text { Moderate violence } \\
\text { stratum }(n=244)\end{array}$ & $\begin{array}{l}\text { High violence } \\
\text { stratum }(n=218)\end{array}$ \\
\hline Geography & Urban & City bordering suburbs & City & Inner city \\
\hline Proportion of sample & $100 \%$ & $38.1 \%$ of entire sample & $32.7 \%$ of entire sample & $29.2 \%$ of entire sample \\
\hline \multicolumn{5}{|l|}{ Gender } \\
\hline Female: & $52.9 \%$ & $53.9 \%$ & $55.7 \%$ & $48.6 \%$ \\
\hline Male: & $47.1 \%$ & $46.1 \%$ & $44.3 \%$ & $51.4 \%$ \\
\hline \multicolumn{5}{|l|}{ Race/ethnicity } \\
\hline African Amer.: & $84.7 \%$ & $74.2 \%$ & $89.9 \%$ & $92.2 \%$ \\
\hline Caucasian: & $3.6 \%$ & $8.5 \%$ & $1.3 \%$ & $0.0 \%$ \\
\hline Hispanic: & $0.8 \%$ & $2.2 \%$ & $0.0 \%$ & $0.0 \%$ \\
\hline AmIndian/Asian: & $1.2 \%$ & $1.1 \%$ & $.8 \%$ & $2.0 \%$ \\
\hline Mixed/Bi-Racial: & $9.7 \%$ & $14.0 \%$ & $8.0 \%$ & $5.8 \%$ \\
\hline \multicolumn{5}{|l|}{ Grade at consent } \\
\hline Second: & $2.4 \%$ & $0.4 \%$ & $2.0 \%$ & $5.5 \%$ \\
\hline Third: & $44.6 \%$ & $55.2 \%$ & $38.1 \%$ & $38.1 \%$ \\
\hline Fourth: & $27.1 \%$ & $21.5 \%$ & $33.2 \%$ & $27.5 \%$ \\
\hline Fifth: & $25.9 \%$ & $22.9 \%$ & $26.7 \%$ & $28.9 \%$ \\
\hline \multicolumn{5}{|l|}{ SES proxy } \\
\hline Free/reduced meals: & $73.8 \%$ & $58.2 \%$ & $66.6 \%$ & $90.0 \%$ \\
\hline Special education services & Yes: $15.9 \%$ & Yes: $19.4 \%$ & Yes: $10.6 \%$ & Yes: $13.3 \%$ \\
\hline
\end{tabular}

communities with low, moderate, and high levels of neighborhood crime. To avoid selection bias and human subjects concerns, race/ethnicity was not used as a selection criterion. The inclusion criteria for students at the time of recruitment were: (1) Enrolled as a full-time student in one of the six identified Baltimore City public elementary schools in the Fall of 2006 or 2007; (2) aged 8-12 years, inclusively; (3) speak English and live with an Englishspeaking parent/guardian. Exclusion criteria included: (1) Presence of serious medical or neurological illness (e.g., epilepsy, closed head trauma) or mental retardation that precluded completion of the interview; or (2) Does not live with at least one parent or legal guardian.

Initial recruitment began in January 2007 and yielded 490 eligible families who consented to participate and comprised Cohort 1; $427(87.1 \%)$ child interviews were conducted in the first semester of fielding the project. The teachers and caregivers of the Cohort 1 students were also interviewed, including $375(88.2 \%)$ teachers and 282 $(66.4 \%)$ parents/caregivers. In the following academic semester (Fall 2007), an additional 256 families consented and comprised Cohort 2. Cohort 2 consisted of third, fourth, and fifth grade students in the six participating schools who were not enrolled in the MORE Project during the previous year due to nonresponse or they were new student transfers. There were a total of 1,119 eligible students across both cohorts representing a $67 \%$ consent rate. School-level means and limited data on all students in grades 3, 4, and 5 were compared with those who consented. Comparing all students in the schools at the beginning of the academic year with those enrolled in the project, there was no difference in the proportion of males $(p>.05)$. There was a slight difference in the proportion who were African American (86\% of participating students versus $93 \%$ of eligible, $p<.01$ ), but that $7 \%$ difference should not affect the generalizability of the results to the population of all students in the selected schools. As such, it is believed that the families who consented to participate in the MORE Project are representative of those who were eligible.

Data collection for Year 2 yielded interviews on over 600 children, 336 from Cohort 1 and 278 from Cohort 2. The current sample (Cohorts 1 and 2 combined) is $85 \%$ African American and 53\% female. At the time of consent, their mean age was 9.6 years old $(S D=1.08$; range $=$ $8-12$ years); $2.4 \%$ of the sample was in second grade, $44.6 \%$ in the third grade, $27.1 \%$ in the fourth grade, and $25.9 \%$ in the fifth grade. Table 2 provides more detail on the demographic characteristics of the total MORE sample.

\section{Participant Recruitment}

The principals at each participating school designated a contact person, typically a member of the school's administrative staff, to assist the MORE Project with administrative requests. These designees provided the 
project with school-wide rosters for each second, third, fourth, and fifth grade classroom to identify the target participant pool. Once identified, rosters were used to personalize two consent packets for every eligible student (i.e., parental consent form, MORE Project lottery form, letter of support/commitment from their school's principal). One consent packet was mailed to the student's home address, the second was distributed in eligible classrooms to each student following a brief explanatory presentation by a MORE Project staff member. The mailings and classroom distributions were further supplemented with follow-up telephone calls to caregivers when there were working phone numbers. For parents/caregivers without telephones and/or for nonresponsive families, specially trained consent gatherers attempted to make home visits to explain the study and obtain parental consent.

Various levels of incentives were provided to encourage students and parents/caregivers to consider participating in the MORE Project. For example, each caregiver who returned the signed MORE Project lottery form was entered into a school-wide lottery for a $\$ 50 \mathrm{Wal}$-Mart gift card whether they declined or assented to participate in the project. Each student who returned the consent and/or lottery form to their teacher received a small incentive (e.g., inflatable globe, key chain, ball). Classroom-wide pizza parties were awarded if $90 \%$ of the eligible students in that class returned the consent and/or lottery form. Other recruitment strategies included informational presentations by the MORE Project Director and Field Coordinator at various school functions, such as Back-to-School Night and Parent-Teacher Organization meetings. Familiarity and trust - the best recruitment tool-take a lot of time to build.

Many factors influence the successful completion of over 1,500 annual MORE Project interviews. Goodwill with the participating schools is of the utmost importance. For example, the school principal influences the tenor of interactions with the school at all levels including other administrators, teachers, and front office staff. Without the support of these persons, it is difficult to conduct a longitudinal study of this magnitude. Transparency in procedures is important to establishing an atmosphere of trust and partnership. Whether the teacher assessment is perceived as burdensome is largely dependent on the principal's overall attitude toward the study. An overview of the project and its demand on teachers, staff, and students was presented at grade-level faculty meetings at each of the six schools. To encourage teacher support and motivation, they were compensated with Wal-Mart gift cards or University checks (range $=\$ 20-\$ 50$ depending on the percentage of responses) for their students' returned lottery forms and/or parental consents, whether families consented or declined.

\section{Data Collection}

Standardized training procedures for interviewers and adherence monitoring to ensure quality delivery of the interviews are necessary for the integrity of the project. Interviewer considerations include training, competence, continuity, and sensitivity to the culture within each school and community. This includes being comfortable and engaging with diverse children, not removing students from core classes, and respecting school rules, scheduled program assemblies, and state-wide testing preparation and administration. Although seemingly simplistic, these considerations are key factors in the successful completion of quality interviews that yield positive experiences for each child. To that end, a teacher at one of the high violence schools observed that the MORE Project interview may be "therapeutic" for the children. She said the students seem to enjoy the interviews and may not frequently, if ever, experience an adult asking them so much about their lives in such an engaging and individualized manner. The teacher's comment was a result of observing the rapport between MORE Project interviewers and the children at her school, as well as positive feedback from the children regarding the interview process.

During the second year of fielding, the interview schedule at each school was revised to reflect a better understanding of the school climate, schedules, and burden to staff and students. Initially, interviewers went to each school one day per week until all child interviews were complete. Interviewer presence for only one day per week was thought to be less burdensome for the schools. During the second year of interviewing, it became clear that it would be less burdensome for the school and a more efficient use of interviewers' time to concentrate on one school at a time. The maximum number of interviewers manageable for a school were assigned to the same school every day until student interviews at that school were complete. To assist in the scheduling process, an online interactive calendar accessible to the coordinator and interviewers was created using Microsoft Office Outlook 2003; it supports multiple-even simultaneous-users who can check their assignments from anywhere.

Annual student interviews were conducted at each school during school hours. First, each school's administrative contact was provided with a list of all students for whom parental consent had been obtained. Based on teacher convenience, attendance, and space availability (often a significant challenge), students were individually released from noncore classes to be interviewed by MORE Project staff. Interviewers briefly introduced the MORE Project and obtained child assent prior to the start of the interview. Rarely, a student might decline to leave a certain class or feel uncomfortable with an unfamiliar interviewer; a 
second attempt to interview the child was always successful and, of over one thousand child interviews, no child declined to participate in an interview.

Students were interviewed in private areas in the school (e.g., empty classrooms, break rooms). The child assessment measures were administered using a combined paperpencil and computerized battery. Examples of paper-pencil administered instruments are the Wechsler scales (i.e., WIAT-II and WASI) which require individual administration following a standardized protocol. For other measures, interviewers read items from laptop screens; students could also read along simultaneously. Students' responses were entered by the interviewers. The computerized assessment battery was programmed using Sensus Multimedia version 2.0 software (Adaptive Technologies Group, Inc. 1994-1997). Sensus Multimedia is a Windows-based program used to construct attractive, easy to follow interviews that facilitate accurate and efficient data collection. It comes with a fully integrated statistics and cross-tabulation package so data can be verified immediately. The average completion time for the child interview was $120 \mathrm{~min}$ (range $=75$ to $180 \mathrm{~min}$ ), completed in one sitting including a light snack and brief break. Upon completion, each child is given a Wal-Mart gift card (Wave 1: $\$ 10$; Wave 2: \$15) as a token of appreciation and a letter to take to their caregiver notifying them that their child finished their interview and requesting them to schedule their parent interview.

The parents/caregivers of children whose interviews had been completed were called to schedule a telephone interview. For hard to reach caregivers, those without telephones, or those who preferred in-person interviews, parent interviews were conducted face-to-face either at the MORE Project offices at Johns Hopkins University or at their child's school. The entire parent interview was administered using a computerized battery and completed within an average of $60 \mathrm{~min}$ (range $=40-180 \mathrm{~min}$ ). Interviewers read each item and the possible answer choices to the caregiver; caregivers' responses were entered by the interviewers on the laptops. Methods for expressing appreciation to parents for their participation include: thank you notes, distribution of Baltimore City Resource Guides, and Wal-Mart gift card incentives (Wave 1: \$40; Wave 2: \$45). The Baltimore City Resource Guides were developed by MORE Project staff and contain information for families on a variety of social, educational, cultural, legal, employment, municipal, physical, and mental health resources. Retaining parents' commitment to the project has been through regular communication by newsletters, children's birthday cards, and other reminder post-cards distributed by mail or in-person via home visits.

Teacher and principal paper-pencil assessments were completed at the end of each school year. Teachers were given a folder containing an informational letter, a survey of general questions about their qualifications and the school/classroom environment, and individualized questionnaires for each consented child in their class (5-10 min per student). Wal-Mart gift cards or University checks were given as a token of appreciation ( $\$ 5$ per student; range $=\$ 20-100)$. Principals and vice-principals completed a brief survey about their teaching qualifications and their school's climate. Principals were given plaques; viceprincipals and administrative staff were given certificates of appreciation. All received \$25 Wal-Mart gift certificates as tokens of appreciation.

\section{Measures}

The MORE Project assessment instruments were selected for their age-appropriateness, psychometric properties, available norms, and when possible, appropriateness for use with ethnic minority youth. The following describes the measures that assess key constructs in the conceptual model (i.e., primary predictor variable, protective factors, risk factors, outcomes; see Fig. 1) as outlined in Fig. 2.

\section{Primary Predictor Variable: Children's Exposure to Chronic Community Violence}

Because community violence is a significant variable in this project, it is important to assess it using multiple methods, informants, and measures. Community violence is related to other forms of violence, several of which are assessed as well (with the exception of parent-child violence, as there were substantial concerns regarding parents' willingness to consent to participate if we were to assess child abuse). Children's exposure to community violence is being assessed using both child and parent report of perceived events. Perceived exposure to violence to community violence may differ from objective accounts of events (e.g., police reports, indicators of neighborhood and social disorder). The Children's Report of Exposure to Violence (CREV; Cooley et al. 1995) is a widely used self-report questionnaire developed to assess children's lifetime exposure to community violence. Community violence is defined as deliberate acts intended to cause physical harm against persons in the community. The types of violent situations include being chased or threatened, beaten up, robbed or mugged, shot, stabbed, or killed. The original CREV has good two-week test-retest reliability $(r=.75)$, internal consistency (overall $\alpha=.78$ ), and construct validity (Cooley et al. 1995).

An additional module was created in a previous project to assess youth's exposure to war and terrorism. Following the terrorist attacks in the United States in September 2001 
and the initiation of the Iraqi war, this "world violence" module was designed to assess the frequency of children's perceived exposure to war and terrorism that may have occurred in their communities, their country, or elsewhere in the world (e.g., attacks on public transportation, chemical or biological attacks, bombs, war). As in the other CREV modules, frequency of exposure to world violence is through four modes (i.e., media, hearsay, direct witness, direct victimization). The CREV-Revised (CREV-R) is comprised of the original 29 items plus world violence items. Its Total score is derived by summing the responses (scored 0-4) on the 45 scored items for the Media, Reported/Hearsay, Witnessed, Victim, and World Violence subscales; higher scores indicate greater exposure. The potential range of scores is from 0 to 180 . The lifetime version of the CREV-R was used at Wave 1, but the pastyear version is being used in Waves 2 and 3 to determine chronicity/severity of violence exposure. The CREV-R has good reliability and validity as demonstrated in a preliminary study of school-based sample of third to fifth grade urban children using a paper-pencil version. Cronbach's $\alpha$ 's for the computerized version of the lifetime CREV-R Total score with the World Violence module is 0.78 , without it is 0.88 . The past-year CREV-R Total score $\alpha$ is 0.89 .

The Children's Report of Exposure to Violence-Parent Report (CREV-P) is a modification of the CREV-R to obtain parent/caregiver's report of their perception of their child's exposure to community violence. Scoring procedures for the CREV-P are generally identical to the CREV, although the Media violence subscale is not asked of the parents. Separate past year and lifetime scores may be computed. Both have good internal consistency in a preliminary study (Cronbach's $\alpha \mathrm{s}=0.93$ and 0.91 , respectively) and in the current study (Cronbach's $\alpha$ s for the computerized version of the lifetime and past-year Total scores are 0.81 and 0.79 , respectively).

Eight items of the short version of the My Exposure to Violence (MyETV; Selner-O'Hagan et al. 1998) structured interview are included in the MORE Project child battery. The past-year portion assesses exposure to violent events that were either witnessed or personally experienced (e.g., shot at, heard gunfire, serious accident, seen dead body). The distinction between violence in the home versus in the community is important to make in community violence research with children (Horn and Trickett 1998), and is permitted by the addition of the MyETV. On a sample of 9to 24-year-old participants from diverse racial/ethnic groups, the MyETV was found to have high internal consistency, test-retest reliability, and good construct validity (Selner-O'Hagan et al. 1998). Reliability estimates based on the sum of the eight individual items in the current study were low (Cronbach's $\alpha=0.45$ ).

\section{Risk Factors}

Demographic characteristics, including socioeconomic status, are reported by parents/caregivers using the Household Structure and Demographics questionnaire. It was created by researchers in the Baltimore Prevention Program at Johns Hopkins University for use in large school-based community-epidemiological studies is asked of parents/caregivers to provide family socio-demographic characteristics for each of the members of the household. It includes level of education, occupational status, ethnicity, employment status, age, and relationship to the target child. Additional information assessed includes self-reported total family income, the child's country of origin, the biological father's and mother's involvement in the child's caregiving, and the number of moves the family has made since the target child was born.

Culture of violence is a broad risk factor that includes indices of the community's pervading attitude toward violence, aggression, and hostility, both as a means to an end and as a symptom, as well as whether it is accepted or not. Included among the measures to assess this construct are the child's report of their Attitudes Toward Violence and Relational Aggression, parent STAXI and CTS1, as well as indices of violence from the neighborhood assessment, NIfETy. Youth's self-reported attitudes toward violence were assessed via five items derived from the Attitude toward Interpersonal Peer Violence Scale (Slaby and Guerra 1988). The scale indicates the perceived legitimization or appropriateness of aggressive responses to threat. Responses across the five items (e.g., "Its okay for me to hit someone if they hit me first") are averaged with higher scores indicating greater support for aggressive behavior. Prior research with this measure reported $\alpha$ 's ranging from 0.75 (Dahlberg et al. 1998) to 0.85 (Bradshaw et al. in press). Parental trait anger is one of six scales from the State-Trait Anger Expression Inventory-2 (STAXI-2, Spielberger 1999) used in the MORE Project to assess angry feelings as a personality trait. This scale is comprised of ten items assessed on a four-point Likert scale to indicate the frequency/intensity of anger over time. Evidence supports the validity and reliability of the STAXI-2 for adolescents and adults (Spielberger 1999). In the MORE Project, the Cronbach's $\alpha$ for the STAXI-2 Trait Anger scale is 0.81 .

Relational aggression is assessed through four items developed by Little et al. (2003) to measure reactive relational aggression. Participants indicate the extent to which they agreed with statements such as, "If others have hurt me, I try to keep them from being in my group of friends," and "When I am upset with others, I ignore them or stop talking to them." Prior research with this measure reported an $\alpha$ of 0.63 and in the MORE Project is very low 
$(\alpha=0.35)$. Parental trait anger is one of six scales from the State-Trait Anger Expression Inventory-2 (STAXI-2, Spielberger 1999) used in the MORE Project to assess angry feelings as a personality trait. This scale is comprised of 10 items assessed on a four-point Likert scale to indicate the frequency/intensity of anger over time. Evidence supports the validity and reliability of the STAXI-2 for adolescents and adults (Spielberger 1999). In the MORE Project, the Cronbach's $\alpha$ for the STAXI-2 Trait Anger scale is 0.81 .

Familial conflict and violence is assessed using the Conflict Tactics Scale-Form R (CTS1-Form R; Straus $1979,1987,1988,1990)$, which is a 13-item parent report of intrafamilial violence used to resolve conflicts. Items are rated on a 6-point Likert scale; higher scores indicate more family conflict and higher levels of coerciveness. There are three subscales (Reasoning, Verbal aggression, and Violence), each of which the parent respondent rates: (a) their own behavior toward their partner (i.e., "participant"); and (b) their partner's behavior toward the participant (i.e., "partner"). No questions regarding parent/caregiver aggression toward their child were asked. The CTS-Form R has high internal consistency, face and concurrent validity, and acceptable construct validity (Straus 1979). In the current sample, the internal consistencies for the Reasoning, Verbal Aggression, and Violence subscales were $\alpha$ 's $=0.69,0.76$, and 0.76, respectively, and for the Participant and Partner scales were 0.72 and 0.69 , respectively.

Characteristics of the neighborhood environment are assessed by the Neighborhood Inventory for Environmental Typology (NIfETy; Furr-Holden et al. 2008). The NIfETy method uses independent evaluators who go to the residential blocks of Baltimore neighborhoods to systematically assess physical and social disorder; indicators of violence, alcohol, and other drug exposure; and positive neighborhood characteristics. Built upon previous methods that assessed neighborhood context to inform child and family health (e.g., Caughy et al. 2001; McDonnell 2007; Raudenbush et al. 2003; Sampson and Raudenbush 1999, 2005), the NIfETy method involves an epidemiological approach to evaluate characteristics of residential neighborhoods that might indicate a change in crime, violence, victimization, and alcohol and other drug exposure in a manner that is quantifiable, replicable, and designed to be longitudinal (Furr-Holden et al. 2008). For the MORE Project, the city unit blocks in which the consented families resided were given to the NIfETy project investigators who sent trained field assessors to make evaluations using Palm OS Zire 31 Personal Digital Assistants (PDAs) programmed with Pendragon Form 5.0 software. For Cohort 1, $98.1 \%$ of the families' neighborhood blocks were assessed. The assessments were conducted in the daytime.
There are 114 quantitative and 15 qualitative items that comprise seven domains assessed by the NIfETy that include positive/healthy and negative indicators: (1) Physical layout of the block face (e.g., length/width of block, alleys present [that run through to next street], dwelling count); (2) Types of structures (e.g., single family/detached homes, liquor stores, churches); (3) Adult activity (e.g., adults watching youth, adults in work uniforms, [male] adults sitting on steps); (4) Youth activity (e.g., youth playing, "corner kids/boys," dangerous youth activities; 5) Physical disorder and order (e.g., abandoned/ vacant structures, new construction or renovation, police present); (6) Social disorder and order (e.g., outdoor community recreation outlets, homeless people, traffic); and (7) Violence and alcohol and other drug indicators (e.g., drug paraphernalia, memorials, obvious signs of drug selling). In an independent sample, internal consistency reliability for the Total NIfTEy scale was good (intra-class coefficient $=0.84) ; \alpha$ coefficients ranged from 0.27 to 0.90 for the subscales; and inter-rater reliability and validity were in the acceptable to good range (Furr-Holden et al. 2008).

Adverse Life Events in the child's life are assessed by both child and parent report on the MESA, respectively. The former is assessed using the Multicultural Events Schedule for Adolescents (MESA; Gonzales et al. 1995). This scale was developed to assess major and minor life events that are specific to an inner city, multi-ethnic population (Gonzales et al. 1995). It was normed on African American and Caucasian youth, as well as English- and Spanish-speaking Mexican American adolescents. The MESA was derived from existing life events scales (e.g., Adolescent Perceived Events Scale, Compas et al. 1987; Adolescent Life Events Checklist, Johnson and McCutcheon 1982) and is comprised of 84 items that occur over the past 3 months. A Total life events score is based on the total number of events endorsed, with a higher score indicating more adverse life events and hassles. There are eight separate subscales: Family Trouble/Change; Family Conflict; Peer Hassles/Conflict; School Hassles; Economic Stress; Perceived Discrimination; Language Conflicts; and Perceived Violence/Personal Victimization. The MESA has concurrent validity and adequate test-retest reliability (two weeks: $r=0.71$; Gonzales et al. 1995). In the current study, the Cronbach's $\alpha$ for the MESA total score is 0.90 .

Parental reports of adverse events that occurred in their child's life are assessed using a modified version of the Multicultural Events Schedule for Adolescents (MESA; Gonzales et al. 1995) created for the MORE Project using five of the eight subscales. This Parent-MESA is comprised of 34 items that occurred over the past year and include the following subscales: Family Trouble/Change, Family Conflict, Economic Stress, and Violence/Personal 
Victimization. In the current study, the Parent-MESA Total score Cronbach's $\alpha$ is 0.86 .

\section{Protective Factors}

Children's Prosocial Coping is assessed by the child's selfreport on the ACOPE and SSRS, as well as teacher reports on the SSRS and TOCA. The Adolescent Coping for Problem Experiences (A-COPE; Patterson and McCubbin 1987) is a youth self-report measure that identifies major coping strategies and behaviors in dealing with general life stress (Schwarzer and Schwarzer 1996). The 54 items rated on a 5-point frequency scale comprise 12 subscales, although only seven of them are used in the MORE Project (i.e., Ventilating Feelings, Seeking Diversions, Solving Family Problems, Avoiding Problems, Seeking Spiritual Support, Investing in Close Friends, and Seeking Professional Support). The A-COPE has been validated within a longitudinal study investigating health-risk behaviors and is appropriate for research on youth stress and health-risk behaviors (Schwarzer and Schwarzer 1996). In the current study, the internal consistency reliability for the A-COPE Total score is $\alpha=0.72$.

The Social Skills Rating System (SSRS; Gresham and Elliott 1990) assesses third through twelfth grade students' social behaviors that may affect student-teacher relationships, peer acceptance, and academic performance (Gresham and Elliott 1990). There are five subscales, two of which are used in the MORE Project: Cooperation and Self-Control. The Cooperation scale includes behaviors such as helping others, sharing materials, and complying with rules and directions (Gresham and Elliott 1990). The Self-Control scale includes behaviors exhibited in conflict (e.g., teasing) and nonconflict (e.g., compromising) situations. Items are rated on a three-point Likert frequency scale. National norms are based on a very large, diverse (e.g., multi-racial, male, female) sample of youth, yielding a median Social Skills Total score coefficient $\alpha$ of 0.90 across all informants (i.e., parent, child, and teacher). Published internal consistency $\alpha$ coefficients for the Cooperation and Self-Control subscales ranged from 0.78 to 0.84 , with acceptable test-retest reliabilities for the Cooperation and Self-Control subscales (Gresham and Elliott 1990). In the MORE Project, internal consistencies for the youth's Social Skills Rating Scale Cooperation and Self-Control subscales are $\alpha=0.74$ and 0.58 , respectively, and the combined SSRS Cooperation and Self-Control $\alpha$ is 0.78 .

The Teacher Form of the SSRS (Gresham and Elliott 1990) individually assesses student's social skills and academic competence using this screening instrument that classifies social behavior in educational and family environments. The Teacher Form of the SSRS is comprised of subscales that assess social skills, problem behaviors and academic competence. The 57 items are rated using 3-point frequency and importance scales. The raw scores from the Social Skills Scale and the Problem Behaviors Scale are converted into age- and gender-normed standard scores ( $M=100 ; S D=15$; Benes 1995) based on a large standardization sample that included regular and special education students, as well as a significant proportion of ethnic minority youth (Benes 1995). The teacher report is psychometrically sound and has good internal consistency, test-retest reliability, and validity (Gresham and Elliott 1990). The Cooperation, Assertion, Self-Control, Internalizing, Externalizing, and Hyperactivity subscales are used in the current study; the Cronbach's $\alpha$ s for those scales range from 0.80 to 0.93 and the Cronbach's $\alpha$ for the Academic Competence scale as 0.96 .

The Teacher Observation of Classroom AdaptationRevised (TOCA-R; Werthamer-Larsson et al. 1991) is a brief measure of each child's adequacy of performance on the core tasks in the classroom as defined and assessed by the teacher. The teacher reports on the adequacy of each child's performance on a six-point scale on six basic tasks: Accepting authority (aggressive behavior); social participation (shy or withdrawn behavior); self-regulation (impulsivity); motor control (hyperactivity); concentration (inattention); and peer likeability (rejection). In addition, the teacher reports on youth's academic performance, behavior, education, substance use, and mental health services s/he perceives each child needs or is receiving. The TOCA-R subscales included in the MORE Project include: Concentration, Aggression, Shy Behavior, Likeability, Hyperactivity, Impulsivity, Proactive Aggression, Oppositional Defiant, and Conduct Problems. Excluding the Shy Behavior scale, whose $\alpha$ was 0.51 , the subscale Cronbach's $\alpha$ s in the MORE Project range from 0.78 to 0.91 .

Cognition and Cognitive Ability are hypothesized as protective factors, including the WASI and Social Information Processing. General cognitive ability is assessed in the MORE Project using two of four subtests of the Wechsler Abbreviated Scale of Intelligence (WASI; Psychological Corporation 1999). The WASI was designed to provide a quick and accurate estimate of an individual's intellectual functioning for screening purposes (Psychological Corporation 1999). The Vocabulary subtest assesses expressive vocabulary, expressive knowledge, verbal knowledge, and fund of information; Matrix Reasoning involves gridded patterns to assess nonverbal reasoning ability (Psychological Corporation 1999). The published WASI test-retest reliability coefficients for the children's sample ranged from 0.86 to 0.93 for the Vocabulary subtest, 0.86 to 0.96 for Matrix Reasoning, and for the twosubtests combined were from 0.85 to 0.88 (Psychological Corporation 1999). 
Social information processing is assessed via a modified version of Dodge and Frame's (1982) series of vignettes describing a hypothetical situation between the participant and a peer (Bradshaw et al. in press). The interviewer reads aloud each scenario and participants state their interpretation of the provocateurs' intent (hostile attribution bias) and their own likely response (aggressive response generation). Using a seven-point coding scheme, independent coders rate intent and response such that higher scores indicate more aggressive hostile attribution biases and aggressive response generation, respectively. Prior research with this measure yielded $\alpha$ s of 0.62 (intent) and 0.63 (response). The correlations among the intent ratings assigned by the three coders for the MORE project ranged from $r=.94, p<.001$ to $r=.96, p<.001$, with an ICC of .95 , indicating a high level of agreement. Similarly, the correlations among the response ratings ranged from $r=.91, p<.001$ to $r=.93, p<.001$, with an ICC of .91 . Ratings were averaged to yield one score per item. The intent and response scores across all four vignettes were averaged, yielding one score for hostile attribution bias $(\alpha=.78)$ and one for response generation $(\alpha=.78)$, respectively. Having lower scores on the intent and response items is hypothesized as more protective.

Parent Psychiatric Health is assessed using the Symptom Checklist-90-Revised (SCL-90-R; Derogatis 1977), a widely used self-report measure designed to assess a broad range of adult psychiatric symptom patterns. There are nine symptom scales and three global scales (i.e., Global Severity Index, Positive Symptom Distress Index; Positive Symptom Total). The nine symptom scales are: Somatization, Obsessive-Compulsive, Interpersonal Sensitivity, Depression, Anxiety, Hostility, Phobic Anxiety, Paranoid Ideation, and Psychoticism. The SCL-90-R has excellent reported reliability and validity (Derogatis and Savitz 2000). In the MORE Project sample, the SCL-90-R total score Cronbach's $\alpha$ is 0.98 . Lower scores on the SCL-90-R are hypothesized as protective.

Healthy Family Environment is being assessed by parent reports on the FES and the PPS. The Family Environment Scale (FES; Moos and Moos 1986), which assesses social and environmental characteristics of the family. There are 10 nine-item subscales including: Cohesion, Expressiveness, Conflict, Independence, Achievement Orientation, Intellectual-cultural orientation, Active-recreational orientation, Moral-religious emphasis, Organization, and Control. The FES is used to measure the parent/caregiver's perceptions of the family environment, deemed an important potential protective factor. In the current study, the Cronbach's $\alpha$ for the Total FES score is 0.77 . The Parenting Practices Scale (PPS) assesses parental involvement, monitoring, and discipline using a five-point Likert scale. Parents/caregivers are asked how frequently over the past month they engaged in positive, developmentally appropriate interactions and communications with their child (i.e., 10-item Parental Involvement subscale), and applied discipline/punishment and its effectiveness (i.e., eight-item Discipline subscale). In the MORE Project, the Cronbach's $\alpha$ s are 0.79 and 0.63 , respectively.

Healthy School Environment is assessed via school administrator, teacher, and child assessments. A background questionnaire is completed by each principal, viceprincipal, and teacher with MORE Project students to provide information on their educational career and teaching certification (e.g., highest degree, year graduated, type of certification). School Climate is measured by a questionnaire that uses a four-point Likert scale to assess the atmosphere of the overall school environment including safety and availability of resources and support from the principal, vice-principal, and teacher's perspective. In the current sample, the Cronbach's $\alpha$ 's for the School Climate items for the principals and teachers are 0.92 and 0.94 , respectively. Teachers also completed the Classroom Climate scale that indicates the general skill level and behavior of all students in their class (in aggregate) on a five-point Likert scale; Cronbach's $\alpha=0.78$. Children's attitudes toward school are assessed via four items administered to the students from the Sense of School Membership Scale (Goodenow 1993). Youth indicate on a four-point Likert scale the extent to which they agree with statements such as, "I feel like I belong at this school" and "The teachers here respect me." Prior research on this measure reported $\alpha$ 's ranging from 0.77 to 0.88 (Dahlberg et al. 1998; Goodenow 1993); the current $\alpha$ reliability coefficient is only 0.57 .

Healthy Neighborhood Environment is the last level of hypothesized protective factor, which includes parent reports, child self-reports, and assessments of positive neighborhood indicators. Positive aspects of the neighborhood environment are assessed using the Collective Efficacy Scale (Sampson et al. 1997) as indicated by the parent/guardian. Collective efficacy is defined as "social cohesion among neighbors combined with their willingness to intervene on behalf of the common good" (Sampson et al. 1997). An extremely large survey of Chicago neighborhood residents showed that collective efficacy has a strong negative association with violence and high between-neighborhood reliability (Sampson et al.). The five-item Informal Social Control subscale $\alpha$ reliability coefficient in the MORE Project is 0.79. Students' perceptions of safety are assessed through the following three items: "I feel safe at my school," "I feel safe in my house," and "I feel safe in my neighborhood." Students indicate the extent to which they agree with each statement on a four-point Likert scale. Prior research on this measure reported an $\alpha$ of 0.63 (Dahlberg et al. 1998) and in this 
project the reliability coefficient is 0.54 . Indicators of healthy neighborhoods as assessed by the NIfETy Method (Furr-Holden et al. 2008) are also hypothesized to protect children from adversities associated with exposure to community violence.

\section{Outcomes}

The adverse outcomes that are hypothesized in the conceptual model to be associated with youth's exposure to chronic community violence include internalizing symptoms, externalizing behaviors, academic difficulties, and substance use.

Internalizing symptoms and externalizing behaviors are assessed using the internalizing and externalizing/hyperactivity scales, respectively, from the Teacher Form of the SSRS (Gresham and Elliott 1990) and particular scales on the TOCA-R (Werthamer-Larsson et al. 1991). Additionally, the Youth Self-Report (YSR; Achenbach 1991), a widely used self-rating of competencies and problems over the past 6 months that parallel those of the Child Behavior Checklist (CBCL; Achenbach 1991) indicates internalizing and externalizing syndromes. The YSR was normed on a large sample of youth of various ethnicities and socioeconomic levels. The test-retest reliabilities ranged from 0.47 to 0.79 and internal consistencies ranged from 0.71 to 0.95 (Achenbach). Although the published recommended minimum age for the YSR is 11 years, communication with a researcher at the YSR publication company (D. Jacobowitz, personal communication, June 24, 2003), Achenbach System of Empirically Based Assessment, clarified that the YSR may be used with younger children, but requires a fifth grade reading level. Standard practice, according to Mr. Jacobowitz, is to read the items aloud to elementary school students below the fifth grade. As such, MORE Project interviewers read the YSR aloud to all student participants. YSR standard scores ( $T$-scores; Mean $=50 ; S D=10$ ) are used in the current project. The subscales used in the MORE Project include: Withdrawn, Somatic Complaints, Anxious/Depressed, Social Problems, Thought Problems, and Attention Problems. The Cronbach's $\alpha$ for the YSR Total score is 0.92 .

Parent reports of their child's internalizing symptoms and externalizing behaviors are assessed using a standardized questionnaire that parallels the Youth Self-Report form. The Child Behavior Checklist-4-18 (CBCL-4-18; Achenbach 1991) is a very widely used instrument (Crijnen et al. 1997) that yields parents' reports of children's competencies and problems in a standardized format. This parent-rated behavior problem checklist yields data on internalizing and externalizing behavior problems as well as social competence (i.e., activities, social, school functioning). The CBCL-4-18 is appropriate for parents of children aged 4-18 years. The behavior problem checklist items are grouped into behavioral syndromes that correspond to the Diagnostic and Statistical Manual, 4th Edition (DSM-IV; American Psychiatric Association 1994) diagnostic categories. The CBCL-4-18 was normed on nationally representative samples, with good to excellent internal consistency and inter-parental agreement (Doll 1998). In the MORE Project, the same subscales in the YSR are used in addition to Delinquent and Aggressive Behavior subscales. For the current study, the Cronbach's $\alpha$ for the CBCL-4-18 Total score is 0.94 .

Two more measures that assess the youth's self-reported externalizing behaviors include the DVPS and bullying. Youth's perpetration of violence is assessed using $D u$ Rant's Youth Violence Perpetration Scale (DVPS). It is a brief self-report measure of different types of lifetime violent and aggressive acts across a range of severity (e.g., "Have you ever been in a gang fight?" "Have you ever carried a weapon?" "Have you ever hurt someone so badly they had to be treated by a doctor or nurse?"). Published psychometric properties are not available. Reliability estimates were calculated on the eight summed items and were low (Cronbach's $\alpha=0.41$ ). Bullying, consistent with Olweus' (1993) definition and that of other large scale studies (e.g., World Health Organization's international study of bullying; Nansel et al. 2001; Spriggs et al. 2007), is defined in the MORE student battery as occurring "when a person or group of people repeatedly say or do mean or hurtful things to someone on purpose." It includes intentional behaviors like teasing, hitting, threatening, namecalling, ignoring, and leaving someone out (Bradshaw et al. 2007). Based on the work of Solberg and Olweus (2003), a threshold of two or more incidents of bullying in the past month is used to determine "frequent" involvement in bullying. No reliability coefficients were calculated because only one item was asked for victimization ("How often have you been bullied during the last month?") and one for perpetration ("How often have you bullied someone else during the last month?").

Academic difficulties are another hypothesized adverse outcome of chronic community violence exposure. Academic achievement in the MORE Project is assessed using the Wechsler Individual Achievement Test-Second EditionAbbreviated (WIAT-II-A; Psychological Corporation 2001) consists of several subtests, two of which are used in this project: Word Reading and Numerical Operations). The WIAT-II-A efficiently assesses basic academic skills and intervention needs in young children through adults. The screener permits the calculation of age- and gradebased standard scores and was standardized using a large representative sample. The WIAT-II-A is widely used, and has demonstrated reliability and validity, with little evidence of practice effects (Psychological Corporation 2001). 
Teacher ratings of academic competence are measured with the Teacher Form of the SSRS, as well as subscales from the TOCA-R. Additionally, academic achievement indicators will be obtained from the Baltimore City Public School System (e.g., attendance, special education status, limited English proficiency, Maryland School Assessment (MSA) and Stanford math and reading scores).

Substance exposure and use, the final hypothesized outcome, is assessed using the Baltimore Substance Use Scale (BSUS; Chilcoat et al. 1995; Chilcoat and Anthony 1996; Kellam and Anthony 1998). The BSUS was developed for use in longitudinal prospective community-epidemiological studies of students in third through eighth grades. It is an adaptation of Elliott and Huizinga's measure of substance use, which they developed for use in the National Survey of Delinquency and Drug Use (Elliot et al. 1985). Youth report on their knowledge, current and/or anticipated use of tobacco, alcohol, marijuana, crack cocaine, heroin, inhalants, and stimulants. Reliability coefficients were not calculated for the MORE Project because individual items are used to reflect intention and drug use patterns.

\section{Data Analyses}

The conceptual model in Fig. 1 drives the analyses that will be conducted using the MORE data. The primary analyses will thus involve estimating the prevalence of exposure to community violence, investigating risk and protective factors for such exposure, and examining outcomes of that exposure. Questions of primary interest will include whether rates of violence exposure differ across violence strata, gender, or race, and whether students with different levels of risk or protective factors, such as family support, have different levels of exposure to violence. Analyses will need to take into account the clustering of students within schools and violence strata, using methods for clustered data such as generalized estimating equations (GEE; Liang and Zeger 1986) or multilevel models (Raudenbush and Bryk 2002). Multilevel models will allow the formal investigation of relationships between variables at both the individual student level and at the level of the school and neighborhood, investigating, for example, how protective factors at both the community level and at the individual level reduce violence exposure. It will also be important to control for other baseline characteristics of the children and their neighborhoods, such as ethnicity, since the neighborhoods differ not just in their violence levels but also in other characteristics. The use of GEE and multilevel models will allow us to include these characteristics as additional predictors of outcomes.
One of the strengths of the MORE Project is the availability of data on many measures from multiple informants, as illustrated in Fig. 2. For example, both the students and their parents provide information on the children's internalizing and externalizing problems (through the YSR and CBCL instruments, respectively), and both the students and their parents also provide information on community violence exposure (through the CREV-R and CREV-P, respectively). This permits systematic investigation of the concordance between child and parent reports, providing additional insight into what those individuals are experiencing and giving researchers in the field of community violence guidance for future data collection. Investigation of the performance of the measures used in the MORE Project also provide valuable information on the use of those measures in a low-income urban environment and whether the standard scales are applicable. When the existing scales do not seem sufficient, the variables will be first grouped based on theory followed by confirmatory factor analysis (Anderson and Gerbing 1988) to identify scale compositions that potentially best fit the MORE Project data. The results could have important implications for future use of these scales.

Another strength of the MORE Project is the availability of longitudinal data for students, with up to 3 years of data available for each child. This is uncommon among community violence studies, particularly those with multiple strata of neighborhood violence. The longitudinal data will allow the calculation of simple correlations over time, to investigate the stability of violence exposure as well as of the risk and protective factors. It will also allow researchers to examine how violence exposure at one time point is associated with outcomes measured later, such as how exposure to violence in 1 year is related to behavior problems the following year. The primary statistical tool to be used in these longitudinal analyses will again be GEE and multilevel models, which can account for both the clustering of observations within children as well as control for year 1 characteristics and demographics (e.g., race, gender) by including them as predictors in the models. More complex GEE models with interaction terms will allow tests of hypotheses such as whether odds of exposure to community violence vary across waves, whether the magnitude of associations vary over time, and whether baseline characteristics such as race/ethnicity or gender moderate the effects of violence exposure. In some cases, the longitudinal data may be used to assess mediators, such as whether parental distress mediates the relationship between exposure to violence and children's behavior, but these analyses will need to be done with care and heavily informed by the conceptual model, as temporality may be hard to determine precisely. 


\section{Discussion}

The MORE Project is a comprehensive, community-based, longitudinal, prospective, and theoretically driven study of children's exposure to community violence. Data analyses have been underway and data collection for additional waves is ongoing. Beyond issues raised previously, there are additional challenges and limitations to the study, some of which are discussed below.

\section{Limitations}

Regarding recruitment, a number of factors impacted the failure to attain the initial target in Wave 1 (e.g., fewer students were available in the participant pool than anticipated based on published school enrollments; year-long delay in obtaining IRB approval for the project thus the grant award was delayed one year; recruitment began in the second semester of school instead of at the beginning of the first semester when we would be perceived as an integrated part of the school environment; no prior relationship existed between the researchers and the participating schools which necessitated "marketing" campaign in an historically conservative climate). Recruitment challenges were further compounded by those that face other studies of urban, primarily ethnic minority families. The caregivers are often challenging to recruit in research, even though all parents in school samples who fail to return consent forms do not necessarily intend to deny their child's participation in the research activities (Hollman and McNamara 1999). The literature indicates as low as a $40 \%$ parental consent rate without using active methods to increase participation (Brooks and Kendall 1982). Although only slightly more than half of the eligible families agreed to participate in the MORE Project, active recruitment strategies were used, enlisting the aid of the principals, teachers, administrators, consultants, and parent helpers, among others.

Following-up families after the first year in which they consented also poses challenges. If the student has changed schools, it is particularly challenging to track and trace the family. The changes in privacy legislation have further complicated previously successful strategies to track and trace parents/caregivers rendering many of those practices no longer effective. These include using social security and driver's license numbers to locate families once they have moved. The advent of cellular phone use which, in many cases among inner-city families, replaces home telephones and are not traceable — particularly those that do not require registration for use. Regarding transfer students, there is generally poor follow-up between the original school and the student's new school for numerous reasons, including parents/caregivers not notifying the old school that they are removing their child and the new system not obtaining school records in a timely fashion. Some students are "lost in the cracks." Another complication in locating families for follow-up assessments is inaccurate home addresses. At the beginning of the school year, contact information is obtained from parents and sent to the schools, although never at $100 \%$ and often with inaccuracies. Despite the dramatic overall differential characteristics between the neighborhoods of each strata as illustrated in Table 1, there may be overlap in the amount and frequency of children's exposure to community violence across the strata. The geographic boundaries of neighborhoods may not eliminate children's exposure to community violence, particularly when the definition and assessment of exposure includes media (television, film, and videogame) and hearing about (reported) violent events. Four of the six MORE Project schools are in zip codes that are contiguous. In past generations, children were less mobile and were more inclined to stay within their neighborhoods. Mass transit, reduced parental monitoring, spending time with friends/relatives outside of their primary residence and other factors may contribute to heterogeneous strata and greater exposure to community violence than one would expect for the low and moderate violence strata. This contributes to the importance of having multiple-and psychometrically soundmethods of assessing youth's exposure to community violence to comprehensively understand its complexities. However, some of the measures assess overlapping constructs, making it challenging to test the conceptual model. Data reduction strategies, such as the creation of composite factors, will be essential to manage such a large number of constructs.

\section{Community Violence and Youth: Treatment} and Prevention

The need for psychosocial treatment and prevention is particularly critical in inner-cities where mental health resources are sparse (Cooley and Lambert 2006). The effects of traumatic events on youth are lessened when the youth has a chance to process those events (Pynoos and Nader 1990), and intervening early in life is most beneficial (Earls 1991; McAlister-Groves et al. 1993). For example, there has been some discussion of whether anxiety serves an inhibitory or protective function by keeping youth who live in violent communities from being further exposed to violence (e.g., fear may motivate them to remain indoors). Another example involves children being at lower risk for aggression if they had some degree of anxiety (Boyd et al. 2003). Although avoidance is sometimes the most appropriate strategy, youth need an array of strategies for handling stressful and anxiety-provoking situations. Those with anxiety, affective, and behavioral problems typically have a limited repertoire. 
There is a paucity of empirically validated, published treatment intervention studies for community violence related distress. Caregivers are important potential mediators in preventing the adverse emotional effects of community violence exposure (e.g., their physical availability, provision of emotional support in working through traumatic events, serving as models of prosocial behavior and coping (Wallen and Rubin 1997). However, that presupposes that the caregivers are themselves prosocial role models. The MORE Project will investigate whether certain parental/caregiver characteristics (e.g., hostility, anger, psychiatric illness) challenge their ability to serve as prosocial role models. Although parents in the MORE Project report on their children's community violence exposure, no direct assessment of parents' own community violence exposure is included, which may mediate their ability to optimally help their children navigate hostile contexts. Increasing children's competence, self-efficacy, and problem solving skills and the inclusion of parents in treatment have been identified as potential strategies to treat youth who have been exposed to violence (Davies and Flannery 1998; Duncan 1996; Garbarino et al. 1991). Promoting parental understanding of child development (Beardslee 2003) may also offset the constraints adult caregivers impose when rearing children in settings with frequent violence (Podorefsky et al. 2001). Active approaches are crucial because many inner-city youth cannot escape direct and indirect exposure to the violence in their communities (e.g., Garbarino et al. 1991; Osofsky et al. 1993).

Poor urban children are among those most vulnerable to the development of emotional and behavioral problems (McKay et al. 1998; Tolan and Henry 1996; Tuma 1989), but the least likely to receive adequate services (Day and Roberts 1991; McKay et al. 1998) and most likely to terminate treatment prematurely (McKay et al. 1996). Schoolbased preventive interventions for children exposed to community violence, particularly those that are held regularly after-school and offer intensive, affordable, yet developmentally appropriate and fun, evidence-based treatments have particular promise because they are not stigmatized as pull-out programs, keep children safe and well monitored in the hours following school and before caregivers are home from work, and offer the intensity needed to adequately apply the intervention. These are under-developed in the literature.

A series of interventions have been created with the intent of altering social-cognitive styles, and thus may benefit children exposed to community violence. One such program called Brain Power (Hudley et al. 1998) was designed to alter the hostile attributional bias through behavioral rehearsal. The intervention targeted third to sixth grade children and had a positive impact on their interpretation of peers' intents in ambiguous situations.
Although the attributional biases were amenable to change through the intervention, the positive impacts on aggressive behavior were relatively short lived. A more intensive small group intervention called Coping Power has been shown to alter social information processing patterns and aggressive behavior in 8- to 13-year-old children (Lochman and Wells 2004). Similar effects were observed in the classroom-based preventive intervention called Making Choices which addresses elementary school children's social cognitive and emotion regulation skills (Fraser et al. 2005). Furthermore, the Metropolitan Area Child Study (MACS) examined the impact of a social-cognitive ecological intervention for aggressive youth in urban and inner-city communities (Eron et al. 2002). This work highlighted the importance of addressing youth, peer, and parent attitudes toward violence to promote sustainable changes in children's beliefs about the appropriateness and effectiveness of aggression.

Prevention and intervention programs typically have minimal impact in producing sustained deterrents to youth violence (Tolan and Guerra 1994) and its concomitants, although there may be more promise for the victims of community violence. It is critical, however, to fully appreciate the multiple influences that compromise urban children's lives (e.g., un-/under-employment, quality of education and housing, family dysfunction (Reese et al. 2001). For example, it is problematic to teach urban youth conflict management skills without addressing the effects of witnessing violence (Jenkins and Bell 1994). Human ecology theory emphasizes the importance of understanding children in context, a critical component in designing effective treatment and preventive interventions (e.g., Bronfenbrenner 1979; Lerner 1995; Lewis et al. 1998). Responding to cultural differences when intervening with youth is essential to improve service delivery (Kazdin 1993). Each community has unique cultural characteristics, strengths and needs; "customizing" interventions when working with specific populations is important (Reese et al. 2001). Well-designed studies of multiple adverse outcomes associated with youth's community violence exposure and associated protective factors are warranted to help design effective school-based preventive and treatment interventions.

\section{Future Research}

Future research should extend community-epidemiological longitudinal studies of urban children from elementary school into and through middle school and beyond. In middle school, childhood problem behaviors that are sequela to violence exposure may become more pronounced, such as academic achievement problems becoming more evident as the achievement gap widens and 
alcohol and substance use emerge. Additional areas that warrant further study are neurocognitive and neurobehavioral functioning associated with youth's exposure to community violence as well as physical health concomitants. Conversely, there are numerous examples of resiliency despite the environmental challenges urban youth experience. Compared to the volume of studies that focus on risk factors, more research is needed on youth's exposure to community violence that focus on protective factors and resilience. Lastly, it would be beneficial to compare the MORE Project data from urban Baltimore to those from other national and international geographical areas (urban, suburban, and rural) and racial/ethnic populations. Although neighborhood crime may be similar among some metropolitan areas, the role of culture as well as immigration challenges may result in differences in the impact of children's exposure to community violence.

Acknowledgments The authors would like to acknowledge those who have assisted with the MORE Project research. We thank our collaborators: Scott Hubbard, Nicholas Ialongo, Phillip Leaf, Megan Bair-Merrit, and Jean Ko. This endeavor is only successful with the ongoing support and cooperation of the Baltimore City Public School System and our six partner schools. The administrators and staff at these schools have provided access and guidance, allowing us to learn from them. We sincerely thank the Baltimore City students and their families who share their lives with us for the betterment of others. We thank the dedicated MORE Team (Alisa, Amber, Andrew, Corina, Dan, Debbie, Katie, Maria, Max, Mike, Lindsay, Steph, Ty, and Winn), with particular appreciation to Kathryn Otte for contributions to this paper. Support and funding for the MORE Project comes from a grant from the National Institute on Drug Abuse to M. Cooley (1 R01 DA018318).

Open Access This article is distributed under the terms of the Creative Commons Attribution Noncommercial License which permits any noncommercial use, distribution, and reproduction in any medium, provided the original author(s) and source are credited.

\section{References}

Achenbach, T. M. (1991). Manual for the youth self-report and 1991 profile. Burlington, VT: University of Vermont, Department of Psychiatry.

Aisenberg, E., \& Ell, K. (2005). Contextualizing community violence and its effects: An ecological model of parent-child interdependent coping. Journal of Interpersonal Violence, 20, 855-871. doi:10.1177/0886260505276833.

Alexander, K. L., Entwisle, D. R., \& Kabbani, N. S. (2001). The dropout process in life course perspective: Early risk factors at home and school. Teachers College Record, 103, 760-822. doi: 10.1111/0161-4681.00134.

American Psychiatric Association (1994). Diagnostic and statistical manual of mental disorders (4th ed.). Washington, DC: Author.

Anderson, J., \& Gerbing, D. (1988). Structural equation modeling in practice: A review and recommended two-step approach. Psychological Bulletin, 103, 411-423. doi:10.1037/0033-2909. 103.3.411.
Attar, B. K., \& Guerra, N. G. (1994). The effects of cumulative violence exposure on children living in urban neighborhoods. Paper presented at the meeting of the American Psychological Society Convention, Washington, D.C.

Attar, B. K., Guerra, N. C., \& Tolan, P. H. (1994). Neighborhood disadvantage, stressful life events, and adjustment in urban elementary school children. Journal of Clinical Child Psychology, 23, 391-400. doi:10.1207/s15374424jccp2304_5.

Baltimore City Data Collaborative (BCDC). (2003). How are we doing? Indicator data on child and family wellbeing. Retrieved August 6, 2008, from http://www.baltimorekidsdata.org.

Bandura, A. (1973). Aggression: A social learning analysis. Englewood Cliffs, NJ: Prentice Hall.

Bandura, A., Ross, D., \& Ross, S. (1961). Transmission of aggression through imitation of aggressive models. Journal of Abnormal and Social Psychology, 63, 575-582. doi:10.1037/h0045925.

Barreto, S., \& McManus, M. (1997). Casting the net for "depression" among ethnic minority children from high-risk urban communities. Clinical Psychology Review, 17, 823-845. doi:10.1016/ S0272-7358(97)00054-8.

Beardslee, W., \& Podorefsky, D. (1988). Resilient adolescents whose parents have serious affective and other psychiatric disorders: The importance of self-understanding and relationships. The American Journal of Psychiatry, 145, 63-69.

Beardslee, W., Versage, E., \& Gladstone, T. (1998). Children of affectively ill parents: A review of the past ten years. Journal of the American Academy of Child and Adolescent Psychiatry, 37, $1134-1141$.

Beardslee, W. R. (2003). Out of the darkened room: When a parent is depressed: Protecting the children and strengthening the family. Boston, MA: Little Brown \& Co.

Bell, C. (1997). Community violence: Causes, prevention, and intervention. Journal of the National Medical Association, 89, 657-662.

Bell, C. C., \& Jenkins, E. J. (1991). Traumatic stress and children. Journal of Health Care for the Poor and Underserved, 2, 175188.

Benes, K. M. (1995). Review of the social skills rating system. In J. C. Conoley \& J. C. Impara (Eds.), The twelfth mental measurements yearbook. Lincoln, NE: Buros Institute of Mental Measurements.

Boivin, M., \& Vitaro, F. (1995). The impact of peer relationships on aggression in childhood: Inhibition through coercion or promotion through peer support. In J. McCord (Ed.), Coercion and punishment in long-term perspectives (pp. 183-197). NY: Cambridge University Press.

Bolton, D., O'Ryan, D., Udwin, O., Boyle, S., \& Yule, W. (2000). The long-term psychological effects of a disaster experienced in adolescence: II: General psychopathology. Journal of Child Psychology and Psychiatry, and Allied Disciplines, 41, 513-523. doi:10.1111/1469-7610.00636.

Boney-McCoy, S., \& Finkelhor, D. (1995). Prior victimization: A risk factor for child sexual abuse and for PTSD-related symptomatology among sexually abused youth. Child Abuse \& Neglect, 19, 1401-1421. doi:10.1016/0145-2134(95)00104-9.

Bowen, N. K., \& Bowen, G. L. (1999). Effects of crime and violence in neighborhoods and schools on the school behavior and performance of adolescents. Journal of Adolescent Research, 14, 319-342. doi:10.1177/0743558499143003.

Boyd, R., Cooley, M., Lambert, S., \& Ialongo, N. (2003). First grade child risk behaviors for community violence in middle school. Journal of Community Psychology, 31, 297-314. doi: 10.1002/jcop.10047.

Bradshaw, C. P., \& Garbarino, J. (2004). Social cognition as a mediator of the influence of family and community violence on adolescent development: Implications for intervention. In J. Devine, J. Gilligan, K. A. Miczek, R. Shaikh, \& D. Pfaff (Eds.), 
Youth violence: Scientific approaches to prevention (pp. 85105). New York: New York Academy of Sciences.

Bradshaw, C. P., Rodgers, C., Ghandour, L., \& Garbarino, J. (in press). Social-cognitive mediators of the association between community violence exposure and aggressive behavior. School Psychology Review.

Bradshaw, C. P., Sawyer, A. L., \& O’Brennan, L. M. (2007). Bullying and peer victimization at school: Perceptual differences between students and school staff. School Psychology Review, 36, 361382.

Bronfenbrenner, U. (1979). The ecology of human development. Cambridge, MA: Harvard University Press.

Brooks, P. H., \& Kendall, E. D. (1982). Working with children. In R. Vasta (Ed.), Strategies and techniques of child study (pp. 325343). New York: Academy.

Brown, D., Ahmed, F., Gary, L., \& Milburn, N. (1995). Major depression in a community sample of African Americans. The American Journal of Psychiatry, 152, 373-378.

Bruce, M., Takeuchi, D., \& Leaf, P. (1991). Poverty and psychiatric status: Longitudinal evidence from the New Haven Epidemiologic Catchment Area Study. Archives of General Psychiatry, 48, 470-474.

Brunswick, A., \& Messeri, P. (1984). Origins of cigarette smoking in academic achievement, stress and social expectations: Does gender make a difference? The Journal of Early Adolescence, 4, 353-370. doi:10.1177/0272431684044006.

Bryant, A., Schulenberg, J., Bachman, J., O’Malley, P., \& Johnston, L. (2000). Understanding the links among school misbehavior, academic achievement, and cigarette use: A national panel study of adolescents. Prevention Science, 1, 71-87. doi:10.1023/ A:1010038130788.

Bureau of Justice Statistics. (1991). Criminal victimization in the United States, 1989. Washington, DC: US Department of Justice.

Burns, M., Morrison, J., Khoury, P., \& Glueck, C. (1980). Blood pressure studies in Black and White inner-city and suburban adolescents. Preventive Medicine, 9, 41-50. doi:10.1016/ 0091-7435(80)90058-4.

Caughy, M. O., O'Campo, P. J., \& Patterson, J. (2001). A brief observational measure for urban neighborhoods. Health \& Place, 7, 225-236. doi:10.1016/S1353-8292(01)00012-0.

Chilcoat, H., \& Anthony, J. (1996). Impact of parent monitoring on initiation of drug use through late childhood. Journal of the American Academy of Child and Adolescent Psychiatry, 35, 91100. doi:10.1097/00004583-199601000-00017.

Chilcoat, H. D., Dishion, T. J., \& Anthony, J. (1995). Parent monitoring and the incidence of drug sampling in urban elementary school children. American Journal of Epidemiology, $141,25-31$.

Christofel, K. (1990). Violent death and injury in US children and adolescents. American Journal of Disease Control, 144, 697706.

Compas, B. E., Davis, G. E., Forsythe, C. J., \& Wagner, B. M. (1987). Assessment of major and daily stressful events during adolescence: The Adolescent Perceived Events Scale. Journal of Consulting and Clinical Psychology, 55, 534-541. doi: 10.1037/0022-006X.55.4.534.

Cooley, M., Boyd, R. C., \& Grados, J. J. (2004). Feasibility of an anxiety preventive intervention for community violence exposed children. The Journal of Primary Prevention, 25, 105-123. doi: 10.1023/B:JOPP.0000039941.85452.ea.

Cooley, M., \& Lambert, S. (2006). School-based interventions for children and adolescents exposed to chronic community violence. In A. Lieberman, R. DeMartino, \& N. Fox (Eds.), Interventions for children exposed to violence. New Jersey: Johnson \& Johnson Pediatric Institute.
Cooley, M. R., Turner, S. M., \& Beidel, D. C. (1995). Assessing community violence: The children's report of exposure to violence (CREV). Journal of the American Academy of Child and Adolescent Psychiatry, 34, 201-208. doi:10.1097/00004583199502000-00015.

Cooley-Quille, M., Boyd, R. C., Frantz, E., \& Walsch, J. (2001). Emotional and psychophysiological impact of exposure to community violence in urban adolescents. Journal of Child Clinical Psychology. Special Section: Violence \& Youth, 30, 199-206.

Cooley-Quille, M. R., \& Lorion, R. (1999). Adolescents' exposure to community violence: Sleep and psychophysiological functioning. Journal of Community Psychology, 27, 367-375. doi: 10.1002/(SICI)1520-6629(199907)27:4<367::AID-JCOP1>3.0. $\mathrm{CO} ; 2-\mathrm{T}$.

Cooley-Quille, M. R., Turner, S. M., \& Beidel, D. C. (1995). The emotional impact of children's exposure to community violence: A preliminary study. Journal of the American Academy of Child and Adolescent Psychiatry, 34, 1362-1368. doi:10.1097/000 04583-199510000-00022.

Cooley-Strickland, M. R., Scharfstein, L. A., \& Beidel, D. C. (2009). Community violence and youth: Prevalence, affect, and behavior. Manuscript submitted for publication.

Crick, N. R., \& Dodge, K. A. (1994). A review and reformulation of social information processing mechanisms in children's social adjustment. Psychological Bulletin, 115, 74-101. doi:10.1037/ 0033-2909.115.1.74.

Crijnen, A., Achenbach, T., \& Verhulst, F. (1997). Comparisons of problems reported by parents of children in 12 cultures: Total problems, externalizing, and internalizing. Journal of the American Academy of Child and Adolescent Psychiatry, 36, 1269-1277. doi:10.1097/00004583-199709000-00020.

Crouch, J. L., Hanson, R. F., Saunders, B. E., Kilpatrick, D. G., \& Resnick, H. S. (2000). Income, race/ethnicity, and exposure to violence in youth: Results from the national survey of adolescents. Journal of Community Psychology, 28, 625-641. doi:10.1002/ 1520-6629(200011)28:6<625::AID-JCOP6>3.0.CO;2-R.

Dahlberg, L. L., Toal, S. B., \& Behrens, C. B. (Eds.). (1998). Measuring violence-related attitudes, beliefs, and behaviors among youth: A compendium of assessment tools. Atlanta, GA: National Center for Injury Prevention and Control of the Centers for Disease Control and Prevention.

Dao, J. (2005, February 9). Baltimore streets meaner, but message is mixed. New York Times. Retrieved August 6, 2008, from http://www.nytimes.com/.

Davies, W. H., \& Flannery, D. J. (1998). Post-traumatic stress disorder in children and adolescents exposed to violence. Pediatric Clinics of North America, 45, 341-353. doi:10.1016/ S0031-3955(05)70010-9.

Day, C., \& Roberts, M. (1991). Activities of the Child and Adolescent Service System Program for improving mental health services for children and families. Journal of Clinical Child Psychology, 20,340-350. doi:10.1207/s15374424jccp2004_2.

Department of Health and Mental Hygiene, AIDS Administration. (2007). Baltimore city HIV/AIDS epidemiological profile. Retrieved August 6, 2008, from http://www.dhmh.state.md.us/ AIDS/.

Derogatis, L. R. (1977). SCL-90-R: Administration. Scoring and procedures manual. Baltimore, MD: Clinical Psychometrics Research.

Derogatis, L. R., \& Savitz, K. L. (2000). The SCL-90-R and Brief Symptom Inventory in primary care. In M. Maruish (Ed.), Handbook of psychological assessment in primary care settings (pp. 297-334). Mahwah, NJ: Lawrence Erlbaum Associates, Inc.

Dodge, K. A. (1985). A social information processing model of social competence in children. In M. Perlmutter (Ed.), Minnesota 
symposium on child psychology (pp. 77-125). Hillsdale, NJ: Lawrence Erlbaum Associates.

Dodge, K. A. (1986). Social information-processing variables in the development of aggression and altruism in children. In C. ZahnWaxler, E. M. Cummings, \& R. Iannotti (Eds.), Altruism and aggression. New York: Cambridge University Press.

Dodge, K., \& Frame, C. L. (1982). Social-cognitive biases and deficits in aggressive boys. Child Development, 53, 620-635. doi: $10.2307 / 1129373$.

Dodge, K. A., \& Pettit, G. S. (2003). A biopsychosocial model of the development of chronic conduct problems in adolescence. Developmental Psychology, 39, 349-371. doi:10.1037/00121649.39.2.349.

Dodge, K. A., \& Somberg, D. R. (1987). Hostile attributional biases among aggressive boys are exacerbated under conditions of threat. Child Development, 58, 213-224. doi:10.2307/1130303.

Doll, B. (1998). Review of the child behavior checklist. In J. C. Impara \& B. S. Plake (Eds.), The thirteenth mental measurements yearbook. Lincoln, NE: Buros Institute of Mental Measurements.

Dossey, L. (1993). Healing words. San Francisco: Harper.

Drug Enforcement Administration (DEA). (2008). Briefs and background, drugs and drug abuse, state fact sheets, Maryland 2008. Retrieved August 6, 2008, from http://www.usdoj.gov/dea/pubs/ states/maryland.html.

Duncan, D. F. (1996). Growing up under the gun: Children and adolescents coping with violent neighborhoods. The Journal of Primary Prevention, 16, 343-356. doi:10.1007/BF02411740.

Duncan, S., Duncan, T., \& Strycker, L. (2000). Risk and protective factors influencing adolescent problem behavior: A multivariate latent growth curve analysis. Annals of Behavioral Medicine, 22, 103-109. doi:10.1007/BF02895772.

DuRant, R., Cadenhead, C., Pendergrast, R., Slavens, G., \& Linder, C. (1994). Factors associated with the use of violence among Black adolescents. American Journal of Public Health, 84, 612-617. doi:10.2105/AJPH.84.4.612.

Earls, F. (1991). A developmental approach to understanding and controlling violence. In H. Fitzgerald, et al. (Eds.), Theory and research in behavioral pediatrics (pp. 61-88). New York: Plenum.

Ellickson, P., \& Morton, S. (1999). Identifying adolescents at risk for hard drug use: Racial/ethnic variations. The Journal of Adolescent Health, 25, 382-395. doi:10.1016/S1054-139X(98)00144-X.

Elliot, D. S., Huizinga, D., \& Ageton, S. S. (1985). Explaining delinquency and drug use. Beverly Hills, CA: Sage Publications.

Ellison, C. G. (1991). Religious involvement and subjective wellbeing. Journal of Health and Social Behavior, 32, 80-99. doi: $10.2307 / 2136801$

Epstein, J., Botvin, G., Diaz, T., Williams, C., \& Griffin, K. (2000). Aggression, victimization and problem behavior among inner city minority adolescents. Journal of Child \& Adolescent Substance Abuse, 9, 51-66. doi:10.1300/J029v09n03_04.

Eron, L., Huesmann, R., Spindler, A., Guerra, N., Henry, D., \& Tolan, P. (2002). A cognitive-ecological approach to preventing aggression in urban settings: Initial outcomes for high-risk children. Journal of Consulting and Clinical Psychology, 70, 179-194. doi:10.1037/0022-006X.70.1.179.

Everett, S., Giovino, G., Warren, C., Crossett, L., \& Kann, L. (1998). Other substance use among high school students who use tobacco. The Journal of Adolescent Health, 23, 289-296. doi: 10.1016/S1054-139X(98)00023-8

Farrell, A. D., \& Bruce, S. E. (1997). Impact of exposure to community violence on violent behavior and emotional distress among urban adolescents. Journal of Clinical Child Psychology, 26, 2-14. doi:10.1207/s15374424jccp2601_1.
Federal Bureau of Investigation (FBI). (1993). Uniform crime reports, 1991. Washington, DC: Department of Justice.

Federal Bureau of Investigation (FBI). (2002). Uniform crime reports, 2002. Washington, DC: Department of Justice.

Federal Bureau of Investigation (FBI), Criminal Justice Information Services Division. (2006a). Crime in the United States by Metropolitan Statistical Area, 2006. Retrieved August 6, 2008, from http://www.fbi.gov/ucr/cius2006/data/table_06.html.

Federal Bureau of Investigation (FBI), Criminal Justice Information Services Division. (2006b). Crime in the United States, 2006. Retrieved August 6, 2008, from http://www.fbi.gov/ucr/cius 2006/index.html.

Fitzpatrick, K. (1993). Exposure to violence and presence of depression among low-income, African-American youth. Journal of Consulting and Clinical Psychology, 61, 528-531. doi: 10.1037/0022-006X.61.3.528.

Fitzpatrick, K. M., \& Boldizar, J. P. (1993). The prevalence of depression among low-income African American youth. Journal of Consulting and Clinical Psychology, 61, 528-531.

Fraser, M. W., Galinsky, M. J., Smokowki, P. R., Day, S. H., Terizan, M. A., Rose, R. A., et al. (2005). Social information-processing skills training to promote social competence and prevent aggressive behaviors in the third grade. Journal of Consulting and Clinical Psychology, 73, 1045-1055. doi:10.1037/0022006X.73.6.1045.

Freeman, L., Mokros, H., \& Poznanski, E. (1993). Violent events reported by normal urban school-aged children: Characteristics and depression correlates. Journal of the American Academy of Child and Adolescent Psychiatry, 32, 419-423. doi:10.1097/ 00004583-199303000-00025.

Furr-Holden, C. D. M., Smart, M. J., Pokorni, J. P., Ialongo, N. S., Holder, H., \& Anthony, J. C. (2008). The NIfETy method for environmental assessment of neighborhood-level indicators of alcohol and other drug exposure. Prevention Science, 9(4), 245255.

Garbarino, J., Kostelny, K., \& Dubrow, N. (1991). No place to be a child: Growing up in a war zone. San Francisco: Jossey-Bass.

Garmezy, N. (1993). Children in poverty: Resilience despite risk. Psychiatry: Interpersonal and Biological Processes, 56, 127136.

Giaconia, R., \& Reinherz, H. (1995). Traumas and posttraumatic stress disorder in a community population of older adolescents. Journal of the American Academy of Child and Adolescent Psychiatry, 34, 1369. doi:10.1097/00004583-199510000-00023.

Gibbs, J. T. (1984). Black adolescents and youth: An endangered species. The American Journal of Orthopsychiatry, 54, 6-21.

Gladstein, J., Rusonis, E. J., \& Heald, F. P. (1992). A comparison of inner-city and upper-middle class youths' exposure to violence. The Journal of Adolescent Health, 13, 275-280. doi: 10.1016/1054-139X(92)90159-9.

Gonzales, N. A., Gunnoe, M. L., Samaniego, R., \& Jackson, K. M. (1995, June). Validation of the Multicultural Events Scale for urban Adolescents (MESA). Paper presented at the Fifth Biennial Conference of the Society for Community Research and Action, Chicago, IL.

Goodenow, C. (1993). The psychological sense of school membership among adolescents: Scale development and educational correlates. Psychology in the Schools, 30, 79-90. doi:10.1002/15206807(199301)30:1<79::AID-PITS2310300113>3.0.CO;2-X.

Gorman-Smith, D., \& Tolan, P. (1998). The role of exposure to community violence and developmental problems among innercity youth. Development and Psychopathology, 10, 101-116. doi:10.1017/S0954579498001539.

Gresham, F. M., \& Elliott, S. N. (1990). Social skills rating system manual. Circle Pines, MN: American Guidance Service. 
Guerra, N. G., Huesmann, L. R., \& Spindler, A. (2003). Community violence exposure, social cognition, and aggression among urban elementary school children. Child Development, 74, 1561-1576. doi:10.1111/1467-8624.00623.

Hampton, R., Gelles, R., \& Harrop, J. (1989). Is violence in Black families increasing? A comparison of 1975 and 1985 national survey rates. Journal of Marriage and the Family, 51, 969-980. doi: $10.2307 / 353209$.

Hill, H. M., \& Madhere, S. (1995). Exposure to community violence and African American children: A multi-dimensional model. Unpublished manuscript, Howard University, Washington, DC.

Hinton-Nelson, M. D., Roberts, M. C., \& Snyder, C. R. (1996). Early adolescents exposed to violence: Hope and vulnerability to victimization. American Journal of Orthopsychiatry, 66, 346353.

Hollman, C. M., \& McNamara, J. R. (1999). Considerations in the use of active and passive parental consent procedures. The Journal of Psychology, 133, 141-156.

Horn, J. L., \& Trickett, P. K. (1998). Community violence and child development: A review of research. In P. Trickett \& C. Schellenbach (Eds.), Violence against children in the family and the community (pp. 103-138). Washington, DC: American Psychological Association.

Hudley, C., Britsch, B., Wakefield, W. D., Smith, T., Demorat, M., \& Cho, S. J. (1998). An attribution retraining program to reduce aggression in elementary school students. Psychology in the Schools, 35, 271-282.

Huizinga, D., Loeber, R., \& Thornberry, T. (1993). Longitudinal study of delinquency, drug use, sexual activity, and pregnancy among children and youth in three cities. Public Health Reports: Journal of the U.S. Public Health Service, 108, 90-96.

Hutcheson, S. P. (1998). Multiple stressors and social-emotional functioning in African American elementary school children (Doctoral dissertation, Howard University, 1998). Dissertation Abstracts International: Section B: The Sciences and Engineering, 59, 0419.

Ialongo, N., Edelsohn, G., Werthamer-Larsson, L., Crockett, L., \& Kellam, S. (1996). The course of aggression in first-grade children with and without co-morbid anxious symptoms. Journal of Abnormal Child Psychology, 24, 445-456.

Institute of Medicine. (1994). New directions in definitions. In P. J. Mrazek \& R. J. Haggerty (Eds.), Reducing risks for mental disorders: Frontiers for preventive intervention research (pp. 19-29). Washington, DC: National Academy Press.

Jenkins, E. (1993). Post-traumatic stress disorder symptoms of African-American youth exposed to violence. Paper presented at the meeting of the American Association of Behavior Therapy, Atlanta, GA.

Jenkins, E. J. (2001). Violence and trauma in the lives of African American children. In A. Neal-Barnett, J. Contreras, \& K. Kerns (Eds.), Forging links: African American children clinical developmental perspectives (pp. 107-128). Westport, CT: Praeger.

Jenkins, E. J., \& Bell, C. G. (1994). Post-traumatic stress disorder and violence among inner city high school students. In S. Friedman (Ed.), Anxiety disorders in African Americans. NY: Springer.

Jessor, R., van den Boss, J., Vanderryn, J., Costa, F., \& Turbin, M. (1995). Protective factors in adolescent problem behavior: Moderator effects and developmental change. Developmental Psychology, 31, 923-933.

Johnson, J. H., \& McCutcheon, S. (1982). Assessing life events in older children and adolescents: Preliminary findings with the Life Events Checklist. In I. Sarason \& C. Spielberger (Eds.), Stress and anxiety. New York: Norton.

Jones, J., \& Barlow, D. H. (1990). The etiology of post-traumatic stress disorder. Clinical Psychology Review, 10, 299-328.
Kandel, D., Kessler, R., \& Margulies, R. (1978). Antecedents of adolescent initiation into stages of drug use: A developmental analysis. Journal of Youth and Adolescence, 7, 13-40.

Kashani, J. H., Deuser, W., \& Reid, J. C. (1991). Aggression and anxiety: A new look at an old notion. Journal of the American Academy of Child and Adolescent Psychiatry, 30, 218-223.

Kashani, J. H., \& Orvaschel, H. (1988). Anxiety disorders in midadolescence: A community sample. American Journal of Psychiatry, 145, 960-964.

Kazdin, A. E. (1993). Adolescent mental health. American Psychologist, 48, 127-141.

Keane, T. M., Gerardi, R. J., Lyons, J. A., \& Wolfe, J. (1988). The interrelationship of substance abuse and PTSD: Epidemiological and clinical considerations. In M. Galanter (Ed.), Recent developments in alcoholism (Vol. V). New York: Plenum Press.

Kellam, S., \& Anthony, J. (1998). Targeting early antecedents to prevent tobacco smoking: Findings from an epidemiologically based randomized field trial. American Journal of Public Health, $88,1490-1495$.

Kendall, P. C., \& Hammen, C. (1995). Abnormal psychology. Boston, MA: Houghton Mifflin Co.

Kilpatrick, D. G., Acierno, R., Saunders, B., Resnick, H. S., Best, C. L., \& Schnurr, P. P. (2000). Risk factors for adolescent substance abuse and dependence: Data from a national sample. Journal of Consulting and Clinical Psychology, 68, 19-30.

Kliewer, W., Lepore, S. J., Oskin, D., \& Johnson, P. D. (1998). The role of social and cognitive processes in children's adjustment to community violence. Journal of Consulting and Clinical Psychology, 66, 199-209.

Koenig, H. G. (1997). Use of religion by patients with severe medical illness. Mind/Body Medicine, 2, 31-36.

Koss-Chiono, J., \& Vargas, L. (1992). Through the looking glass: A model for understanding culturally responsive psychotherapies. In L. Vargas \& J. Koss-Chiono (Eds.), Working with culture: Psychotherapeutic interventions with ethnic minority children and adolescents. San Francisco, CA: Jossey-Bass.

Kubiak, C. H. S. (1998). The relationship between community crime level and the manifestation of anxiety in a referred sample of children (Doctoral dissertation, Auburn University, 1998). Dissertation Abstracts International Section Al: Humanities \& Social Sciences, 58, 2546.

Ladd, G. W., \& Burgess, K. B. (1999). Charting the relationship trajectories of aggressive, withdrawn, and aggressive/withdrawn children during early grade school. Child Development, 70, 910929.

Ladd, G. W., \& Kochenderfer-Ladd, B. J. (2002). Identifying victims of peer aggression: Analysis of cross-informant data for concordance, estimation of relational adjustment, prevalence of victimization. Psychological Assessment, 14, 1-23.

LaGreca, A., Silverman, W., \& Wasserstein, S. (1998). Children's pre-disaster functioning as a predictor of post-traumatic stress following hurricane Andrew: A prospective study. Journal of Consulting and Clinical Psychology, 64, 712-723.

Last, C. G., \& Perrin, S. (1993). Anxiety disorders in African American and White children. Journal of Abnormal Child Psychology, 21, 153-164.

Leonard, H. L., Goldberger, E. L., Rapoport, J. L., Cheslow, D. L., \& Swedo, S. E. (1990). Childhood rituals: Normal development or obsessive-compulsive symptoms? Journal of the American Academy of Child and Adolescent Psychiatry, 29, $17-23$.

Lerner, R. (1995). America's youth in crisis: Challenges and options for programs and policies. Thousand Oaks, CA: Sage.

Lewis, J. A., Lewis, M. D., Daniels, J. H., \& D’Andrea, M. J. (1998). Community counseling: Empowerment strategies for a diverse society. Pacific Grove, CA: Brooks-Cole. 
Liang, K.-Y., \& Zeger, S. L. (1986). Longitudinal data analysis using generalized linear models. Biometrika, 73, 13-22.

Linares, L. O., Heeren, T., Bronfman, E., Zuckerman, B., Augustyn, M., \& Tronick, E. (2001). A meditational model for the impact of exposure to community violence on early child behavior problems. Child Development, 72, 639-652.

Lipsitz, S. R., Molenberghs, G., Fitzmaurice, G. M., \& Ibrahim, J. (2000). GEE with Gaussian estimation of the correlations when data are incomplete. Biometrics, 56, 528-536.

Little, T., Henrich, C., Jones, S., \& Hawley, P. (2003). Disentangling the "whys" from the "what's" of aggressive behaviour. International Journal of Behavioral Development, 27, 122-133.

Lochman, J. E., \& Wells, K. C. (2004). The Coping Power program for preadolescent aggressive boys and their parents: Outcome effects at the 1-year follow-up. Journal of Consulting and Clinical Psychology, 4, 571-578.

Loeber, R., \& Keenan, K. (1994). Interaction between conduct disorder and its comorbid conditions: Effects of age and gender. Clinical Psychology Review, 14, 497-523.

Lorion, R. (1998). Exposure to pervasive community violence: Contamination of the school environment. In D. S. Elliott, K. Williams, \& B. Hamburg (Eds.), Violence in American schools (pp. 293-311). New York: Cambridge University Press.

Lorion, R. L., Brodsky, A., \& Cooley-Quille, M. R. (1999). Exposure to urban violence: A framework for conceptualizing risky settings. In D. E. Biegel, \& A. Blum (Eds.), Innovations in practice and service delivery across the lifespan (pp. 124-143). New York: Oxford.

Luthar, S., Cicchetti, D., \& Becker, B. (2000). The construct of resilience: A critical evaluation and guidelines for future work. Child Development, 71, 543-562.

Mackesy-Amiti, M., \& Fendrich, M. (2000). Trends in inhalant use among high school students in Illinois: 1993-1995. American Journal of Drug and Alcohol Abuse, 26, 569-590.

March, J. S., \& Parker, J. D. (1999). The multidimensional anxiety scale for children (MASC). In M. Maruish (Ed.), The use of psychological testing or treatment planning and outcomes assessment (2nd ed., pp. 299-322). Mahwah, NJ: Lawrence Erlbaum.

Marks, I. (1987). Fears, phobias and rituals. New York: Oxford University Press.

Martinez, P., \& Richters, J. E. (1993). The NIMH community violence project: II. Children's distress symptoms associated with violence exposure. Psychiatry: Interpersonal and Biological Processes, 56, 22-35.

McAlister-Groves, B., Zuckerman, B., Marans, B., \& Cohen, D. (1993). Silent victims: Children who witness violence. Journal of the American Medical Association, 269, 262-264.

McDonnell, J. R. (2007). Neighborhood characteristics, parenting, and children's safety. Social Indicators Research, 83, 177199.

McKay, M., McCadam, K., \& Gonzales, J. (1996). Addressing the barriers to mental health services for inner-city children and their caretakers. Community Mental Health Journal, 32, 353-361.

McKay, M., Stoewe, J., McCadam, K., \& Gonzales, J. (1998). Increasing access to mental health services for urban children and their caregivers. Health and Social Work, 23, 9-15.

Moos, R. H., \& Moos, B. S. (1986). The family environment scale: The manual. Palo Alto, CA: Consulting Psychologists Press.

Morris, R. J., \& Kratochwill, T. R. (1983). Treating children's fears and phobias: A behavioral approach. Elmsford, NY: Pergamon Press.

Mowrer, O. H. (1960). Learning theory and the symbolic processes. New York: Wiley.

Mulvey, E., Odgers, C., Skeem, J., Gardner, W., Schubert, C., \& Lidz, C. (2006). Substance use and community violence: A test of the relation at the daily level. Journal of Consulting and Clinical Psychology, 74, 743-754.

Mushe-Eizenman, D. R., Boxer, P., Danner, S., Dubow, E. F., Goldstein, S. E., \& Heretick, D. M. L. (2004). Social-cognitive mediators of the relation of environmental and emotion regulation factors to children's aggression. Aggressive Behavior, 30, 389-408.

Myers, H. F., Taylor, S., Alvy, K. T., Arrington, A., \& Richardson, M. A. (1992). Parental and family predictors of behavior problems in inner-city Black children. American Journal of Community Psychology, 20, 557-576.

Nalven, F. B. (1970). Manifest fears and worries of ghetto vs. middleclass suburban children. Psychological Reports, 27, 285-286.

Nansel, T. R., Overpeck, M., Pilla, R. S., Ruan, W. J., SimmonsMorton, B., \& Scheidt, P. (2001). Bullying behaviors among US youth: Prevalence and association with psychosocial adjustment. Journal of American Medical Association, 285, 2094-2100.

Neal, A. M., \& Baskett, D. (1993). North and South: A comparative study of African American children's fears. Unpublished manuscript, Kent State University.

Neal, A. M., \& Brown, B. J. W. (1994). Fears and anxiety disorders in African American children. In S. Friedman (Ed.), Anxiety disorders in African Americans (pp. 65-75). New York, NY: Springer Publishing Company.

Neal, A., \& Turner, S. (1991). Anxiety disorders research with African Americans: Current status. Psychological Bulletin, 109, 400-410.

Obot, I., \& Anthony, J. (2000). School dropout and injecting drug use in a national sample of White non-Hispanic American adults. Journal of Drug Education, 30, 145-155.

Olweus, D. (1993). Bullying at school. Oxford, England: Blackwell.

Osofsky, J. D. (1995). The effects of exposure to violence on young children. American Psychologist, 50, 782-788.

Osofsky, J. D., Werers, S., Hann, D. M., \& Fick, A. C. (1993). Chronic community violence: What is happening to our children? Psychiatry, 56, 36-45.

Overstreet, S., \& Braun, S. (1999). A preliminary examination of the relationship between exposure to community violence and academic functioning. School Psychology Quarterly, 14, 380396.

Parker, R., \& Auerhahn, K. (1998). Alcohol, drugs, and violence. Annual Review of Sociology, 24, 291-311.

Patterson, J. M., \& McCubbin, H. I. (1987). Adolescent coping style and behaviors: Conceptualizations and measurement. Journal of Adolescence, 10, 153-186.

Pfefferbaum, B., Nixon, S., Tivis, R., Doughty, D., Pynoos, R., Gurwitch, R., et al. (2001). Television exposure in children after a terrorist incident. Psychiatry: Interpersonal and Biological Processes, 64, 202-211.

Podorefsky, D., Beardslee, W., \& McDonald-Dowdell, M. (2001). Adaptation of preventive interventions for use in a low-income culturally diverse community. Journal of the American Academy of Child and Adolescent Psychiatry, 40, 879-886.

Psychological Corporation. (1999). Wechsler Abbreviated Scale of Intelligence Manual. San Antonio, TX: Author.

Psychological Corporation. (2001). Wechsler Individual Achievement Test Screener. San Antonio, TX: Author.

Pynoos, R. S. (1993). Traumatic stress and developmental psychopathology in children and adolescents. In J. Oldham, M. Riba, \& A. Tasman (Eds.), Review of Psychiatry (pp. 205-237). Washington, DC: American Psychiatric Press.

Pynoos, R. S., Frederick, C., Nader, K., \& Arroyo, W. (1987). Life threat and post-traumatic stress in school-age children. Archives of General Psychiatry, 44, 1057-1063.

Pynoos, R. S., \& Nader, K. (1990). Children's exposure to violence and traumatic death. Psychiatry Annals, 20, 334-344. 
Pynoos, R., Steinberg, A., \& Piacentini, J. (1999). A developmental psychopathology model of childhood traumatic stress and intersection with anxiety disorders. Biological Psychiatry, 46, $1542-1554$.

Raudenbush, S. W., \& Bryk, A. S. (2002). Hierarchical linear models: Applications and data analysis methods (2nd ed.). Thousand Oaks, CA: Sage.

Raudenbush, S., Johnson, C., \& Sampson, R. J. (2003). A multivariate, multilevel Rasch Model with application to self-reported criminal behavior. Sociological Methodology, 29, 1-41.

Reese, L. E., Vera, E. M., Thompson, K., \& Reyes, R. (2001). A qualitative investigation of perceptions of violence risk factors in low-income African American children. Journal of Clinical Child Psychology, 30, 199-206.

Resnick, M., Bearman, P., Blum, R., Bauman, K., Harris, K., Jones, J., et al. (1997). Protecting adolescents from harm: Findings from the National Longitudinal Study on Adolescent Health. Journal of the American Medical Association, 278, 823-832.

Richters, J. E., \& Martinez, P. (1993). The NIMH community violence project: Children as victims and witnesses to violence. Psychiatry, 56, 7-21.

Rosenberg, M., O'Carrol, P., \& Powell, K. (1992). Violence is a public health problem. Journal of the American Medical Association, 267, 3071-3072.

Rutter, M. (1987). Psychosocial resilience and protective mechanisms. American Journal of Orthopsychiatry, 57, 316-331.

Rutter, M. (1990). Commentary: Some focus and process considerations regarding effects of parental depression on children. Developmental Psychology, 26, 60-67.

Rutter, M., \& Quinton, D. (1977). Psychiatric disorder: Ecological factors and concepts of causation. In H. McGurk (Ed.), Ecological factors in human development (pp. 173-187). Amsterdam: North-Holland.

Saltzman, W. R. (1996). Exposure to community violence and the prediction of violent antisocial behavior in a multi-ethnic sample of adolescents (Doctoral dissertation, University of Maryland, College Park, 1996). Dissertation Abstracts International: Section : The Sciences and Engineering, 57, 2223.

Sameroff, A., Bartko, W., Baldwin, A., Baldwin, C., \& Seifer, R. (1998). Introduction: Family and social influences on the development of child competence. In M. Lewis \& C. Feiring (Eds.), Families, risk, and competence (pp. 161-185). Mahwah, NJ: Erlbaum.

Sampson, R. J., \& Raudenbush, S. W. (1999). Systematic social observation of public spaces: A new look at disorder in urban neighborhoods. American Journal of Sociology, 105, 603-651.

Sampson, R. J., \& Raudenbush, S. W. (2005). Neighborhood stigma and the perception of disorder. Focus, 24, 7-11.

Sampson, R. J., Raudenbush, S. W., \& Earls, F. (1997). Neighborhoods and violent crime: A multilevel study of collective efficacy. Science, 277, 918-924.

Scheeringa, M., \& Zeanah, C. (1995). Symptom expression and trauma variables in children under 48 months of age. Infant Mental Health Journal, 16, 259-270.

Schubiner, H., Scott, R., \& Tzelepis, A. (1993). Exposure to violence among inner-city youth. Journal of Adolescent Health, 14, 214 219.

Schwab-Stone, M. E., Ayers, T. S., Kasprow, W., Voyce, C., Barone, C., Shriver, T., et al. (1995). No safe haven: A study of violence exposure in an urban community. Journal of the American Academy of Child and Adolescent Psychiatry, 34, 1343-1352.

Schwab-Stone, M., Chen, C., Greenberger, E., Silver, D., Lichtman, J., \& Voyce, C. (1999). No safe haven II: The effects of violence exposure on urban youth. Journal of the American Academy of Child \& Adolescent Psychiatry, 38, 359-367.
Schwartz, D., \& Gorman, A. (2003). Community violence exposure and children's academic functioning. Journal of Educational Psychology, 95, 163-173.

Schwarz, N. (1999). Self-reports: How the questions shape the answers. American Psychologist, 54, 93-105.

Schwarz, E. D., \& Kowalski, J. M. (1991). Malignant memories: PTSD in children and adults after a school shooting. Journal of the American Academy of Child and Adolescent Psychiatry, 30, 936-944.

Schwarzer, R., \& Schwarzer, C. (1996). A critical survey of coping instruments. In M. Zeidner \& N. Endler (Eds.), Handbook of coping: Theory, research, applications. New York, NY: Wiley.

Selner-O'Hagan, M. B., Kindlon, D. J., Buka, S. L., Raudenbush, S. W., \& Earls, F. J. (1998). Assessing exposure to violence in urban youth. Journal of Child Psychology and Psychiatry and Allied Disciplines, 39, 215-224.

Shahinfar, A., Fox, N., \& Leavitt, L. (2000). Preschool children's exposure to violence: Relation of behavior problems to parent and child reports. American Journal of Orthopsychiatry, 70, $115-125$.

Shakoor, B. H., \& Chalmers, D. (1991). Co-victimization of AfricanAmerican children who witness violence: Effects on cognitive, emotional, and behavioral development. Journal of the National Medical Association, 83, 233-238.

Shaw, J. A. (2003). Children exposed to war/terrorism. Clinical Child and Family Psychology Review, 6, 237-246.

Singer, M., Anglin, T., Song, L., \& Lunghofer, L. (1995). Adolescents' exposure to violence and associated symptoms of psychological trauma. Journal of the American Medical Association, 273, 477-482.

Slaby, R. G., \& Guerra, N. G. (1988). Cognitive mediators of aggression in adolescent offenders: I. Assessment. Developmental Psychology, 24, 580-588.

Smith, S. K., Steadman, G. W., \& Minton, T. D. (1999). Criminal victimization and perceptions of community safety in 12 cities. Washington, DC: US Department of Justice.

Solberg, M., \& Olweus, D. (2003). Prevalence estimation of school bullying with the Olweus Bully/Victim Questionnaire. Aggressive Behavior, 29, 239-268.

Spielberger, C. D. (1999). State-trait anger expression inventory-2. Odessa, Fl: Psychological Assessment Resource Inc.

Spriggs, A. L., Iannotti, R. J., Nansel, T. R., \& Haynie, D. L. (2007). Adolescent bullying involvement and perceived family, peer and school relations: Commonalities and differences across race/ ethnicity. Journal of Adolescent Health, 41, 283-293.

Straus, M. A. (1979). Measuring intrafamily conflict and violence: The Conflict Tactics (CT) Scales. Journal of Marriage and the Family, 41, 75-88.

Straus, M. A. (1987). Is child abuse increasing? Evidence from the National Family Violence Resurvey. Paper presented at the Conference on Child Abuse, American Association for Protecting Children, Austin, Texas.

Straus, M. A. (1988). Measuring Psychological and Physical Abuse of Children with the Conflict Tactics Scale. Durham, NH: Family Research Laboratory, University of NH.

Straus, M. A. (1990). The Conflict Tactics Scale and its critics: An evaluation and new data on validity and reliability. In M. A. Straus \& R. J. Gelles (Eds.), Physical violence in American families: Risk factors and adaptations to violence in 8, 145 families (pp. 75-91). New Brunswick, NJ: Transaction Publishing.

Stuber, J., Fairbrother, G., Galea, S., Pfefferbaum, B., Wilson, G. M., \& Vlahov, D. (2002). Determinants of counseling for children in Manhattan after the September 11 attacks. Psychiatric Services, $53,815-822$. 
Swanson, C. B. (2004). Projections of 2003-04 high school graduates: Supplemental analyses based on findings from who graduates? who doesn't? Retrieved April 20, 2009, http://www.urban.org/ publications/411019.html.

Taylor, R. J., Tucker, M. B., Chatters, L. M., \& Jayakody, R. (1997). Recent demographic trends in African American family structure. In R. Taylor, J. Jackson, \& L. M. Chatters (Eds.), Family life in Black America (pp. 14-62). Thousand Oaks, CA: Sage Publications.

Thomas, S. P., \& Groer, M. W. (1986). Relationship of demographic, life-style and stress variables to blood pressure in adolescents. Nursing Research, 35, 169-172.

Tiet, Q., Bird, H., Davies, M., Hoven, C., Cohen, P., Jensen, P., et al. (1998). Adverse life events and resilience. Journal of the American Academy of Child and Adolescent Psychiatry, 37, 1191-1200.

Tolan, P., \& Guerra, N. (1994). Prevention of delinquency: Current status and issues. Applied \& Preventive Psychology, 3, 251-273.

Tolan, P. H., Guerra, N. G., \& Montaini-Klovdahl, L. R. (1997). Staying out of harm's way: Coping and the development of inner-city children. In S. Wolchik \& I. Sandler (Eds.), Handbook of children's coping: Linking theory and intervention. New York: Plenum Press.

Tolan, P., \& Henry, D. (1996). Patterns of psychopathology among urban poor children: Co-morbidity and aggression effects. Journal of Consulting and Clinical Psychology, 64, 1094-1099.

Tuma, J. (1989). Mental health services for children: The state of the art. American Psychologist, 44, 188-198.

Turner, S., Beidel, D., \& Cooley-Quille, M. (1997). Social effectiveness therapy: A therapist's guide. Toronto: MHS.

Turner, J., \& Lloyd, D. (1999). The stress process and the social distribution of depression. Journal of Health and Social Behavior, 40, 374-404.

Uehara, E., Chalmers, D., Jenkins, E. J., \& Shakoor, B. (1996). African-American youth encounters with violence: Results from the Chicago community mental health council violence project. Journal of Black Studies, 26, 768-781.

Wallen, J., \& Rubin, R. H. (1997). The role of the family in mediating the effects of community violence on children. Aggression and Violent Behavior, 2, 33-41.

Walters, S. T., \& Bennett, M. E. (2000). Assessing client's spirituality and religious behavior: Recommendations for research and practice in mental health settings. The Behavior Therapist, 23, 79-90.

Weisz, J., Weiss, B., Wasserman, A., \& Rintoul, B. (1987). Controlrelated beliefs and depression among clinic-referred children and adolescents. Journal of Abnormal Psychology, 96, 58-63.

Werthamer-Larsson, L., Kellam, S., \& Wheeler, L. (1991). Effect of first-grade classroom environment on shy behavior, aggressive behavior, and concentration problems. American Journal of Community Psychology, 19, 585-602.

White, H. R. (1990). The drug use-delinquency connection in adolescence. In R. Weisheit (Ed.), Drugs, crime and the criminal justice system (pp. 215-256). Academy of Criminal Justice Sciences Monograph. Highland Heights, KY: Anderson.

White, H. R. (1997). Alcohol, illicit drugs, and violence. In D. Stoff \& J. Breiling (Eds.), Handbook of antisocial behavior (pp. 511523). New York: Wiley.

White, K. S., Bruce, S. E., Farrell, A. D., \& Kliewer, W. (1998). Impact of exposure to community violence on anxiety: A longitudinal study of family social support as a protective factor for urban children. Journal of Child and Family Studies, 7, 187203.

Wills, T., Sandy, J., \& Yaeger, A. (2001). Time perspective and earlyonset substance use: A model based on stress-coping theory. Psychology of Addictive Behaviors, 15, 118-125.

World Health Organization. (2002). World Report on Violence and Health. Brussels, Belgium: WHO. 